\title{
Validation Studies for Numerical Simulations of Flow Phenomena Expected in the Lower Plenum of a Prismatic VHTR Reference Design
}

Richard W. Johnson

September 2005

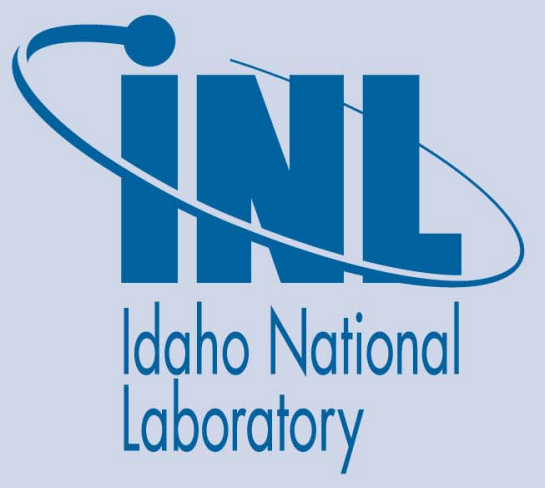

The INL is a U.S. Department of Energy National Laboratory operated by Battelle Energy Alliance 


\title{
Validation Studies for Numerical Simulations of Flow Phenomena Expected in the Lower Plenum of a Prismatic VHTR Reference Design
}

\author{
Richard W. Johnson
}

September 2005

Idaho National Laboratory

Idaho Falls, Idaho 83415

Prepared for the

U.S. Department of Energy

Office of Nuclear Energy

Under DOE Idaho Operations Office

Contract DE-AC07-05ID14517 


\section{EXECUTIVE SUMMARY}

The final design of the very high temperature reactor (VHTR) of the fourth generation of nuclear power plants (Gen IV) has not yet been established. The VHTR may be either a prismatic (block) or pebble bed type. It may be either gas-cooled or cooled with an as yet unspecified molten salt. However, a conceptual design of a gas-cooled VHTR, based on the General Atomics GT-MHR, does exist and is called the prismatic VHTR reference design. The present validation studies are based on the prismatic VHTR reference design. In the prismatic VHTR reference design, the flow in the lower plenum will be introduced by dozens of turbulent jets issuing into a large crossflow that must negotiate dozens of cylindrical support columns as it flows toward the exit duct of the reactor vessel. The jets will not all be at the same temperature due to the radial variation of power density expected in the core. However, it is important that the coolant be well mixed when it enters the power conversion unit to ensure proper operation and long life of the power conversion machinery. Hence, it is deemed important to be able to accurately model the flow and mixing of the variable temperature coolant in the lower plenum and exit duct. Accurate flow modeling involves determining modeling strategies for the simulations, especially the turbulence model employed. It also involves validation of the computer code and turbulence model against a series of separate and combined flow phenomena and selection of the data used for the validation. The present report describes progress made to date for the task entitled 'CFD software validation of jets in crossflow' which was designed to investigate the issues pertaining to the validation process.

A list of separate and combined flow phenomena that will occur to some extent in the lower plenum or that represent simpler components of combined flows includes

- $\quad$ single and multiple jet flow into quiescent surroundings

- $\quad$ single and multiple round jet flow into cross-flows of different relative strengths

- $\quad$ single and multiple round jets into confined cross-flows with local obstructions (support columns)

- $\quad$ flow in tube banks

A set of validation problems would encompass some or all of these flow phenomena and perhaps others. The problem set should be chosen by experienced members of the gas-cooled reactor community. The data used to support the problem set should also be selected by experienced members of the computational fluid dynamics (CFD) community. The first flow phenomenon chosen to investigate is flow in a staggered tube bank because this is shown by preliminary simulations to be the location of the highest turbulence intensity in the lower plenum. Figure ES-1 shows preliminary computations of flow in the lower plenum and the exit hot duct, colored by turbulence intensity from a view above and a side view. The commercial CFD code FLUENT was chosen for the simulations because INL currently has FLUENT licenses and experience using the code. 


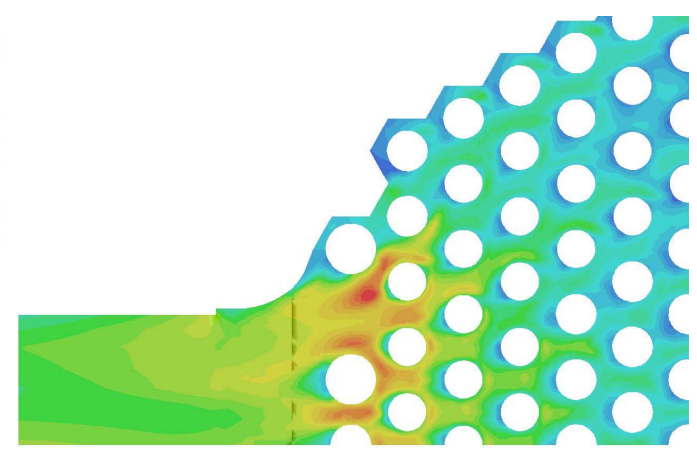

(a)

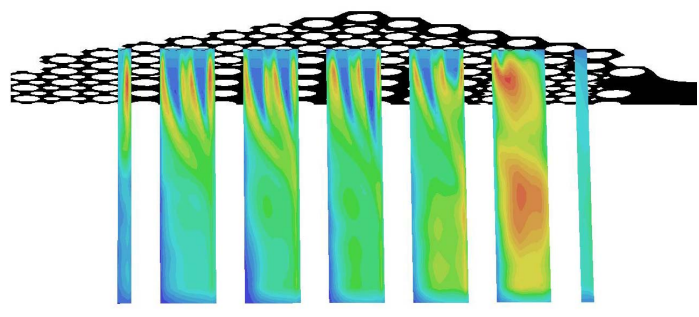

(b)

Figure ES-1. Contours of turbulence intensity in the lower plenum showing (a) a view from above of flow toward the exit duct and (b) a side view of the jet flow into the lower plenum.

Modeling strategies, including the turbulence model employed, for the flow in a staggered tube bundle were investigated using FLUENT. The flow geometry is given by Figure ES-2. The flow entering at the left is set to the same values as the flow exiting at the right. The same is true for top and bottom.

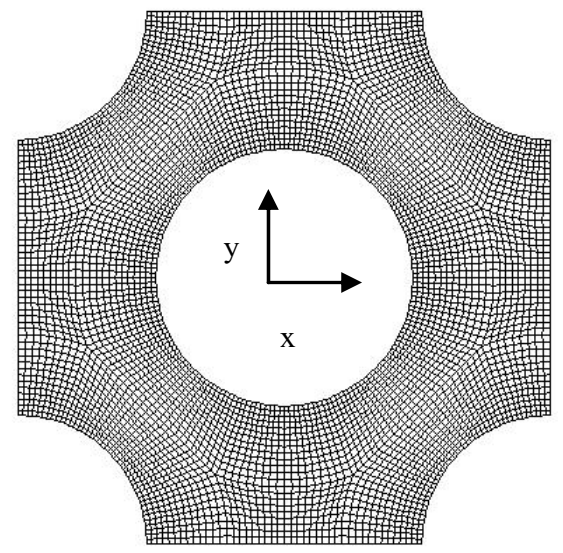

Figure ES-2. Geometry and grid used to investigate flow in a staggered tube bundle.

The best results compared to experimental data were found using the more complex Reynolds stress model for the turbulence. Figure ES-3 illustrates results for three turbulence models for the mean velocity in the $\mathrm{x}$-direction and for the turbulent shear stress for $\mathrm{x}=0$ (above the center tube in Figure ES2 ). The turbulence models are the realizable $\mathrm{k} \sim \varepsilon$ model, the $\mathrm{v} 2 \mathrm{f}$ model (a modified version of the $\mathrm{k} \sim \varepsilon$ model) and the Reynolds stress model.

None of the models employed was completely satisfactory. Other observations are that the numerical analyst must ensure for himself that results are converged to a sufficiently tight tolerance on a sufficiently refined grid; more complex turbulence simulation strategies which compute the turbulence more directly are promising. Future studies will be made of single and multiple jets flowing into quiescent surroundings as well as into cross-flows. Studies should also be made using the more advanced turbulence simulation method of large eddy simulation (LES) to compare with the approach that employs traditional turbulence models. 


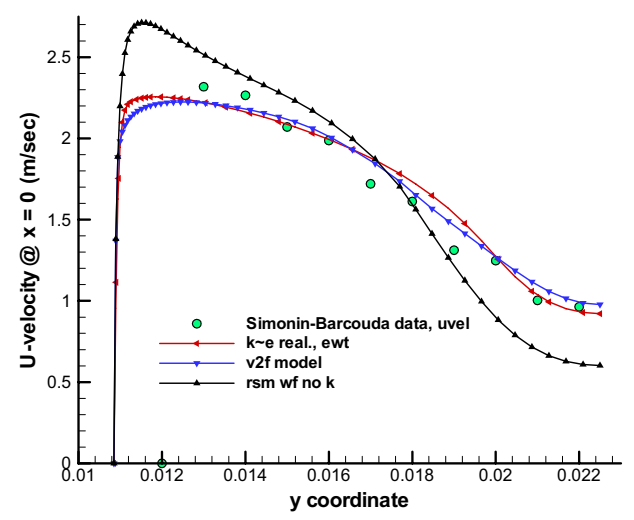

(a)

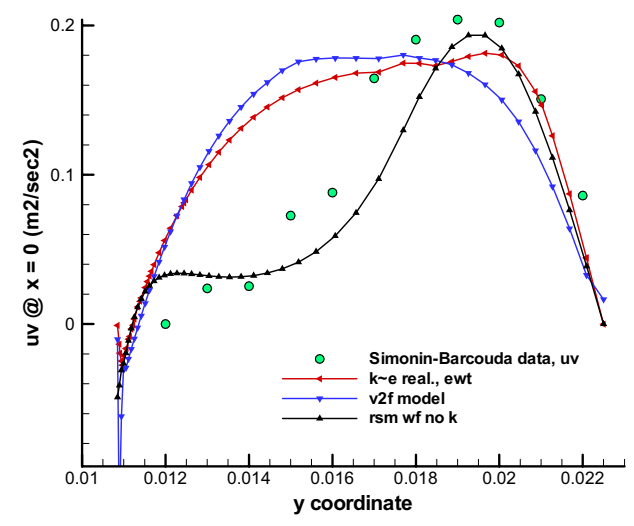

(b)

Figure ES-3. Computations for the (a) mean velocity in the $\mathrm{x}$-direction and (b) the turbulent shear stress for $\mathrm{x}=0$ for three turbulence models. 


\section{CONTENTS}

EXECUTIVE SUMMARY

1. INTRODUCTION 1

2. VALIDATION STUDIES OF CFD SOFTWARE 2



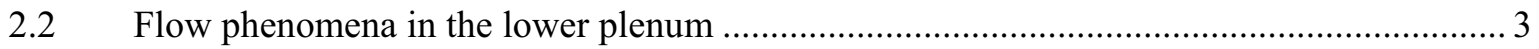

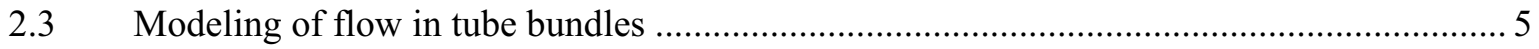

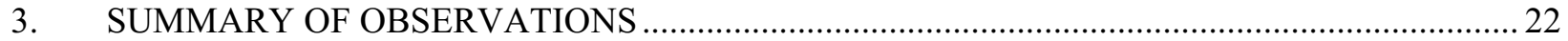

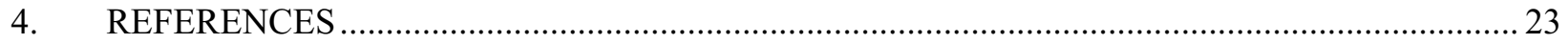

\section{FIGURES}

ES-1. Contours of turbulence intensity in the lower plenum showing (a) a view from above of flow toward the exit duct and (b) a side view of the jet flow into the lower plenum...................... iv

ES-2. Geometry and grid used to investigate flow in a staggered tube bundle. ........................................ iv

ES-3. Computations for the (a) mean velocity in the x-direction and (b) the turbulent shear stress for $\mathrm{x}=0$ for three turbulence models. $\mathrm{V}$

1. Layout of the power conversion unit and reactor vessel for the gas-cooled prismatic VHTR reference design [courtesy of General Atomics (GA)].

2. Graphite fuel blocks showing (a) the TRISO coated fuel particle in the fuel compacts placed in the hex block shown in perspective and (b) plan views (courtesy of General Atomics).

3. Flow phenomena of lower plenum showing (a) jets combining above lower plenum and (b) path lines of flow colored by temperature $(\mathrm{K})$ in the lower plenum.

4. Contours of turbulence intensity in the lower plenum showing (a) a plan view of flow toward the exit duct and (b) a side view of jet flow into the cross-flow.

5. Finite volume grids for the tube bundle simulations (a) coarsest, (b) coarser, (c) finer and (d) finest. The coordinate system is shown.

6. $\mathrm{y}^{+}\left(\equiv \mathrm{u}_{\tau} \mathrm{y} / \mathrm{v}\right)$ distribution for the (a) coarser grid and (b) the finer grid.

7. Comparison of solutions for iterative tolerances of $1 \times 10^{-3}$ to $1 \times 10^{-6}$ for (a) the mean streamwise velocity $U$, (b) the mean transverse velocity $V$, (c) the transverse normal stress $\overline{v^{2}}$ and (d) and the shear stress $\overline{u v}$.

8. Results for (a) $\mathrm{U}$ and (b) $\mathrm{V}$ for the $\mathrm{k} \sim \varepsilon$ model for standard and nonequilibrium wall functions and the enhanced wall treatment compared to the data of S\&B. 
9. Results for the mean (a) streamwise and (b) transverse velocity for the standard $\mathrm{k} \sim \mathcal{\varepsilon}$ turbulence model using standard wall functions for three different grids at $\mathrm{x}=0$.

10. Simulations for the (a) normal and (b) shear Reynolds stresses for the $\mathrm{k} \sim \varepsilon$ model employing standard wall functions and the enhanced wall treatment.

11. Comparisons of mean (a) streamwise and (b) transverse velocities at $\mathrm{x}=0.011 \mathrm{~m}$ with

S\&B data for the standard wall functions and the enhanced wall treatment.

12. Comparisons of (a) normal and (b) shear Reynolds stresses at $x=0.011 \mathrm{~m}$ with $\mathrm{S} \& \mathrm{~B}$ data for the standard wall functions and the enhanced wall treatment.

13. Mean (a) $\mathrm{U}$ and (b) $\mathrm{V}$ velocities at $\mathrm{x}=0$ for the standard, $\mathrm{RNG}$ and realizable $\mathrm{k} \sim \varepsilon$

models all employing the enhanced wall treatment compared to the S\&B data.

14. Comparisons with the S\&B data for the (a) normal and (b) shear stresses for the standard, RNG and realizable $\mathrm{k} \sim \varepsilon$ models, all using the enhanced wall treatment.

15. Results for mean (a) $U$ and (b) $V$ velocities for the realizable $\mathrm{k} \sim \varepsilon$ model using the enhanced wall treatment, the $\mathrm{k} \sim \omega$ model using shear stress transport (SST) and the Reynolds Stress Model (RSM) using wall functions for fine and coarsest grids at $\mathrm{x}=0$.

16. Results for (a) $\overline{u^{2}}$ and (b) $\overline{v^{2}}$ stresses and (c) the shear stress $\overline{u v}$ for the realizable $\mathrm{k} \sim \varepsilon$ model using the enhanced wall treatment, the $\mathrm{k} \sim \omega$ model using shear stress transport and the RSM using wall functions for the fine and coarsest grids at $\mathrm{x}=0$.

17. Results for mean (a) $U$ and (b) $V$ velocities for the realizable $\mathrm{k} \sim \varepsilon$ model using the enhanced wall treatment, the $\mathrm{k} \sim \omega$ model using shear stress transport (SST) and the RSM using wall functions for the finer and coarsest grids at $\mathrm{x}=11 \mathrm{~mm}$.

18. Results for (a) $\overline{u^{2}}$ and (b) $\overline{v^{2}}$ and (c) the shear stress $\overline{u v}$ for the realizable $\mathrm{k} \sim \varepsilon$ model using the enhanced wall treatment, the $\mathrm{k} \sim \omega$ model using shear stress transport and the RSM using wall functions for the finer and coarsest grids for $\mathrm{x}=11 \mathrm{~mm}$.

19. Mean velocity profiles at $\mathrm{x}=0$ for realizable $\mathrm{k} \sim \varepsilon, \mathrm{v}^{2}-\mathrm{f}$ and $\mathrm{RSM}$ (no $\mathrm{k}$ option) models.

20. Results for (a) $\overline{u^{2}}$ and (b) $\overline{v^{2}}$ normal stresses and (c) the shear stress $\overline{u v}$ for the realizable $\mathrm{k} \sim \varepsilon$ model using the enhanced wall treatment, the $\mathrm{v}^{2}$-f model and the RSM using wall functions, but no extra equation for $\mathrm{k}$, all on the finer grid at $\mathrm{x}=0$.

21. Contours for the mean streamwise velocity $\mathrm{U}(\mathrm{m} / \mathrm{sec})$ at time 2.828 seconds using detached eddy simulation (DES).

22. Results for DES for the (a) mean streamwise and (b) transverse velocities compared to the data of $\mathrm{S} \& \mathrm{~B}$ and other results.

23. Results for DES for Reynolds stresses (a) $\overline{u^{2}}$ and (b) $\overline{v^{2}}$ compared to the S\&B data and results for the realizable $\mathrm{k} \sim \varepsilon$ and RSM models.

24. Results for DES for the mean velocities at $1 / 4,1 / 2$ and $3 / 4$ of the depth of the gird compared to RSM results and the S\&B data.

25. Results for DES for the normal Reynolds stresses $\overline{u^{2}}$ and $\overline{v^{2}}$ at $1 / 4,1 / 2$ and $3 / 4$ of the depth of the grid compared to RSM results and the S\&B data. 


\section{Validation Studies for Numerical Simulations of Flow Phenomena Expected in the Lower Plenum of a Prismatic VHTR Reference Design}

\section{INTRODUCTION}

The final design of the very high temperature reactor (VHTR) of the fourth generation of nuclear power plants (Gen IV) has not yet been established. The VHTR may be either a prismatic (block) or pebble bed type. It may be either gas-cooled or cooled with an as yet unspecified molten salt. However, a conceptual design of a gas-cooled VHTR, based on the General Atomics GT-MHR, does exist and is called the prismatic VHTR reference design, MacDonald et al [2003], General Atomics [1996]. The present validation studies are based on the prismatic VHTR reference design. In the prismatic VHTR reference design, the flow in the lower plenum will be introduced by dozens of turbulent jets issuing into a large crossflow that must negotiate dozens of cylindrical support columns as it flows toward the exit duct of the reactor vessel. The jets will not all be at the same temperature due to the radial variation of power density expected in the core. However, it is important that the coolant be well mixed when it enters the power conversion unit to ensure proper operation and long life of the power conversion machinery. Hence, it is deemed important to be able to accurately model the flow and mixing of the variable temperature coolant in the lower plenum and exit duct. Accurate flow modeling involves determining modeling strategies including the fineness of the grid needed, iterative convergence tolerance, numerical discretization method used, whether the flow is steady or unsteady, and the turbulence model and wall treatment employed. It also involves validation of the computer code and turbulence model against a series of separate and combined flow phenomena and selection of the data used for the validation. The present report describes progress made to date for the task entitled 'CFD software validation of jets in crossflow' which was designed to investigate the issues pertaining to the validation process. 


\section{VALIDATION STUDIES OF CFD SOFTWARE \\ 2.1 Layout of the VHTR reactor vessel}

The prismatic VHTR reference design is illustrated in Figure 1. The power conversion system or unit (PCU) is shown on the left while the reactor vessel is on the right. As shown, the coolant moves annularly through the hot duct as it returns from the PCU and annularly up the vessel wall of the reactor vessel into the upper plenum. The coolant then moves downward through the reactor core and into the lower plenum. Finally, the heated coolant flows out of the lower plenum and then through the center of the hot duct back to the PCU. The core has an annular layout with an inner and an outer reflector as well as upper and lower reflectors (graphite blocks shown as white blocks in Figure 1). There are 102 heated graphite columns in the annular core. Each heated column has a stack of ten heated blocks plus additional unheated blocks above and below the heated ones. The fuel is contained in small ( 1 $\mathrm{mm} \mathrm{dia.)} \mathrm{spherical}$ particles called TRISO particles which are then compacted into fuel pins.

Figure 2 illustrates the TRISO particles, the fuel compacts and the graphite blocks with the fuel pins inserted from both a perspective and a plan view. The plan view illustrates the layout of the fuel pins (blue) and the surrounding coolant channels (red). The fuel pins are $12.45 \mathrm{~mm}$ in diameter while the coolant channel diameters are 15.88 and $12.70 \mathrm{~mm}$ in diameter. Some of the blocks contain holes for the control rods, Fig. 2a.

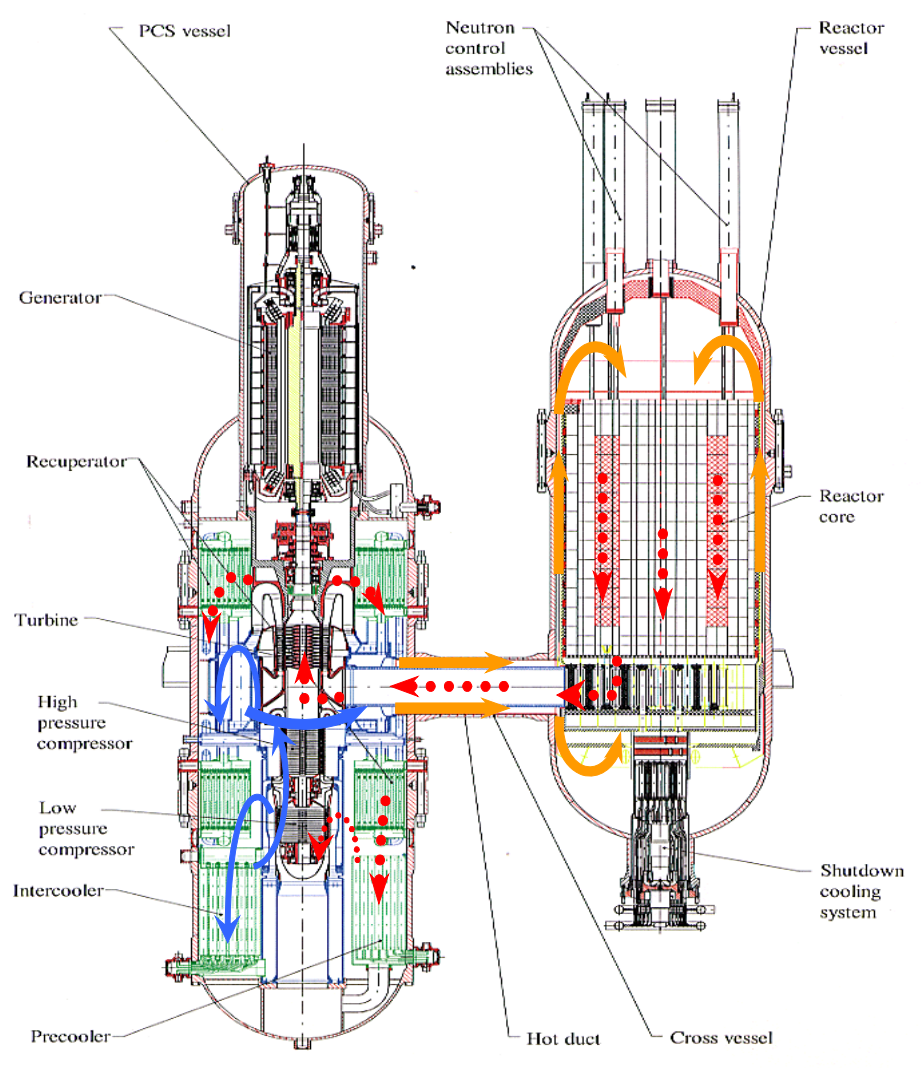

Figure 1. Layout of the power conversion unit and reactor vessel for the gas-cooled prismatic VHTR reference design [courtesy of General Atomics (GA)]. 

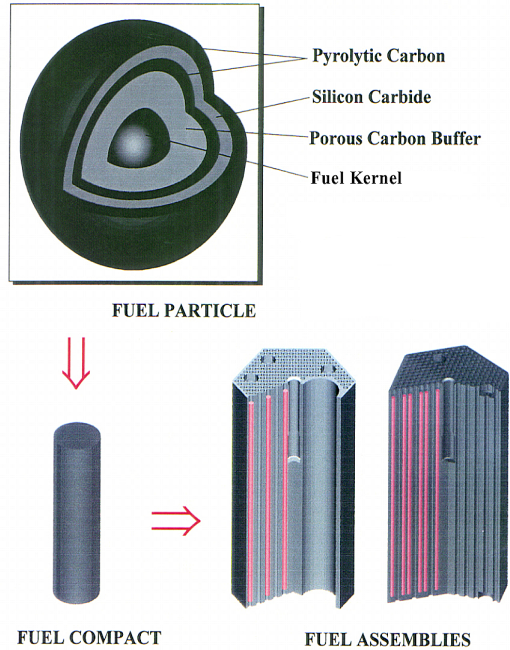

(a)

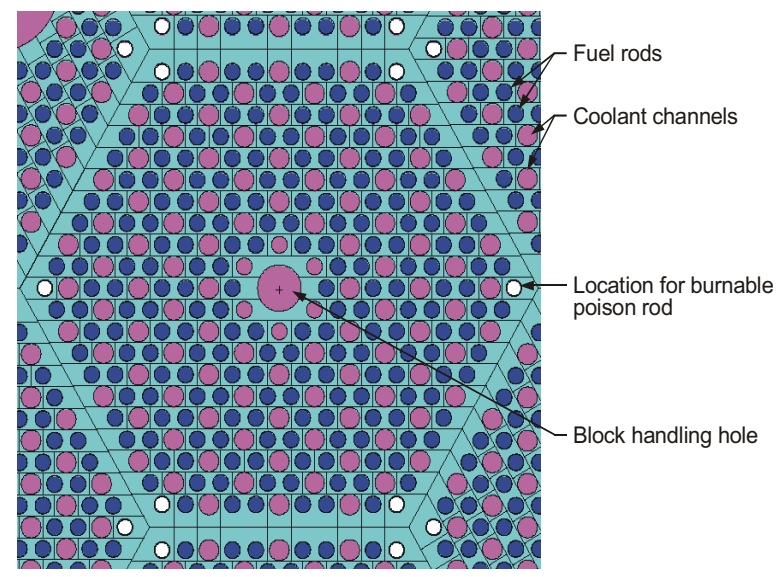

(b)

Figure 2. Graphite fuel blocks showing (a) the TRISO coated fuel particle in the fuel compacts placed in the hex block shown in perspective and (b) plan views (courtesy of General Atomics).

\subsection{Flow phenomena in the lower plenum}

The hundreds of coolant channels in the VHTR core will combine in some fashion into larger ducts just before entering the lower plenum. Figure 3 a illustrates a potential design for coolant channels combining just above the lower plenum. There will still be dozens of heated jets entering into the lower plenum (in an annular region). Figure $3 \mathrm{~b}$ is a preliminary calculation of path lines of the coolant in the lower plenum colored by temperature, showing the entering jets. The lower plenum is populated with dozens of columns to support the graphite blocks in the core. These columns will affect the jets as they enter into the plenum. As the coolant enters the lower plenum, it will be turned ninety degrees to flow towards the exit hot duct. Hence, there will be a cross-flow of coolant towards the exit duct. The crossflow will have to negotiate the support columns and will also experience an expanding flow area on the side away from the exit duct and a converging flow as it approaches the exit duct.

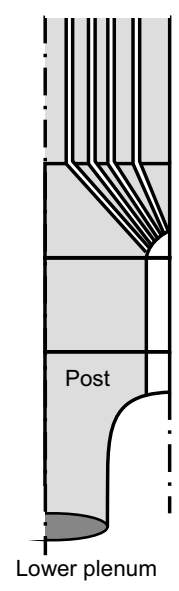

(a)

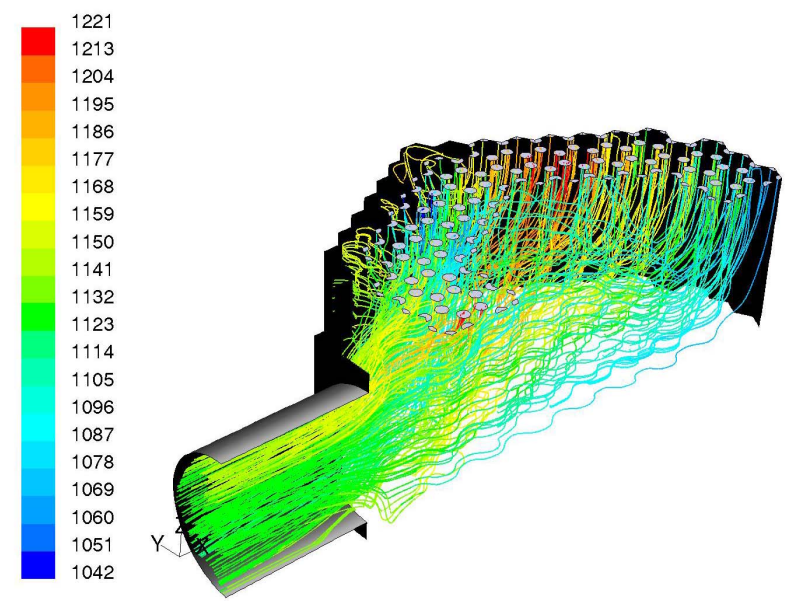

(b)

Figure 3. Flow phenomena of lower plenum showing (a) jets combining above lower plenum and (b) path lines of flow colored by temperature $(\mathrm{K})$ in the lower plenum. 
Figure 4 shows contours of turbulence intensity for a plan view of flow near the exit duct and for a side view of jets flowing into the lower plenum between support columns. The turbulence intensity is greatest in the converging flow region near the exit duct.

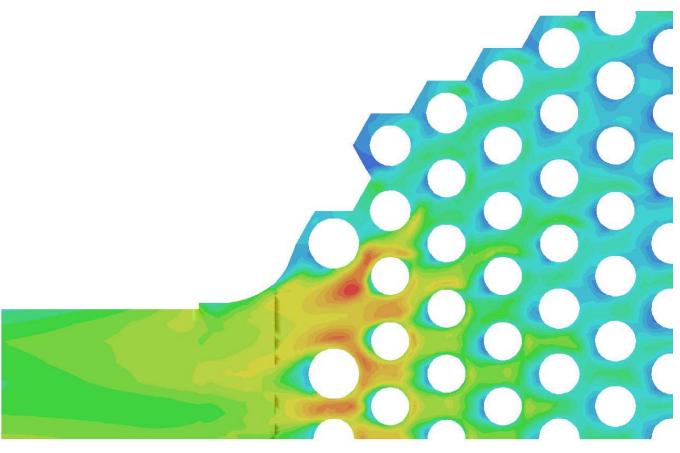

(a)

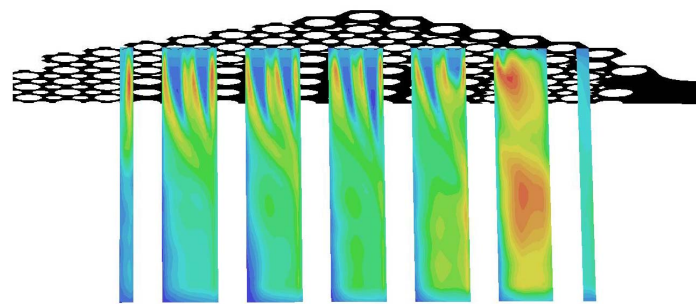

(b)

Figure 4. Contours of turbulence intensity in the lower plenum showing (a) a plan view of flow toward the exit duct and (b) a side view of jet flow into the cross-flow.

Though the flow calculations illustrated in Figures 3 and 4 are unvalidated, they do provide insight into the flow phenomena in the lower plenum. Firstly, the speed of sound based on about $950^{\circ} \mathrm{C}$ and 7.1 $\mathrm{MPa}$ is about $2000 \mathrm{~m} / \mathrm{sec}$ according to the NIST database $\mathrm{a}^{\mathrm{a}}$; the maximum velocity magnitude calculated in the lower plenum is about $100 \mathrm{~m} / \mathrm{sec}$ leading to a Mach number of about 0.05 , indicating that the flow is solidly in the incompressible flow regime. Because the coolant channels combine into larger channels as indicated in Figure 3a, the flow is not fully developed coming into the lower plenum. Certainly the flow is turbulent in the coolant channels, but it is not clear what profile will exist in the larger combined channels (because the design is not set). It is likely that the coolant streams from the various upper channels emptying into the larger channels will be close to the same temperature such that the extent of mixing in the larger channel will have a small effect.

As the flow enters the lower plenum proper, the jets will not only have some interaction with each other, but also with the support columns which are located fairly close together as shown in Figure $4 \mathrm{~b}$. The location of a jet will have a significant effect on its interaction with the cross-flow. Farther away from the exit duct, the cross-flow will be weaker. Hence, these jets will penetrate deeper into the lower plenum than those closer to the exit duct. The latter jets will enter into a stronger and strengthening crossflow with a higher turbulence intensity as indicated in Figure 4.

The cross-flow will have similarities with flow in tube banks. However, the flow coming from straight across from the exit duct will see flow in staggered tube banks, while flow coming from wider angles will be closer to flow through in-line tube banks. The flow in the lower plenum will apparently be turbulent as may be deduced from the fact that the turbulence intensity predicted is relatively large for the preliminary calculations above. The flow may also be unsteady in places, especially where there is highspeed flow around support columns with little or no interference from columns in their downstream wake, Fig. 4a.

While the above flow phenomena are quite complicated, it is possible to list a number of separate and combined flow phenomena that will occur to some extent in the lower plenum or that represent

\footnotetext{
${ }^{\mathrm{a}} \mathrm{http} / / /$ webbook.nist.gov/chemistry/fluid/
} 
simpler components of combined flows. Validation of modeling strategies should include simplified as well as more complicated combined flows. These include

- $\quad$ single round jet flow into quiescent surroundings

- $\quad$ multiple round jets into quiescent surroundings

- $\quad$ single round jet flow into cross-flows of different relative strengths

- multiple round jets into confined cross-flows of different relative strengths

- $\quad$ single round jets into confined cross-flows with local obstructions (support columns)

- $\quad$ multiple round jets into cross-flows with local obstructions (support columns)

- $\quad$ flow in staggered tube banks

- $\quad$ flow in in-line tube banks

A set of validation problems would encompass some or all of these flow phenomena and perhaps others. The initial problem set should be chosen by experienced members of the gas-cooled reactor community. The data used to support the problem set should also be selected by experienced members of the CFD community. To begin an effort to create a selection committee for the latter task, a workshop was held at the 2005 summer meeting of the Fluids Engineering Division of ASME ${ }^{b}$.

Inasmuch as an official problem set has not been chosen nor data approved, the present task represents an investigation into the main issues that will need to be addressed for the validation process. The validation process will require the validation of modeling strategies including which computational fluid dynamics (CFD) code(s) and which turbulence simulation strategy(ies) to use. Initially, some preliminary calculations using an available commercial CFD code, namely FLUENT [2005], are made to investigate the suitability of FLUENT and its suite of turbulence simulation capabilities to model the type of phenomena that will be present in the lower plenum of the block VHTR. Because the highest values of turbulence intensity are shown to be near the exit duct where the flow resembles flow in tube banks, the first flow to be examined was chosen to be flow in a staggered array of tubes. The staggered flow in a tube bank of Simonin and Barcouda [1986, 1988] is used for comparison. The 1988 reference for Simonin and Barcouda are for the same apparatus as the 1986 data with measurements extended up to the sixth row. Both references are given along with the data on the ERCOFTAC database ${ }^{c}$. The data of Simonin and Barcouda were used in a comparison study for turbulence models for the $2^{\text {nd }}$ and $3^{\text {rd }}$ ERCOFTACIAHR workshops [1993,1994]. The data are provided for comparing turbulence model results and have been used for comparison with numerical simulations, e.g. Benhamadouche and Laurence [2003], RolletMiet et al [1999], Hassan and Barsamian [2004], and Moulinec et al [2004].

\subsection{Modeling of flow in tube bundles}

The flow of fluid for isothermal flow is governed by conservation of momentum and mass as given by the Navier-Stokes and continuity equations. In general, these equations are time-dependent. The traditional approach to solving these equations for turbulent flow is to perform Reynolds averaging of the

\footnotetext{
${ }^{\mathrm{b}}$ ASME Fluids Engineering Summer Conference, June 19-23 2005, Houston, Texas

${ }^{\mathrm{c}}$ http://cfd.me.umist.ac.uk/ercoftac/
} 
equations. The length of the time average should be sufficient to ensure that the mean quantities so defined do not vary from time interval to time interval. Reynolds averaging involves a decomposition of the dependent variables of velocity, pressure and temperature into a mean quantity and a fluctuating quantity:

$\phi=\Phi+\phi^{\prime}$

where $\phi$ is the instantaneous quantity, $\Phi$ is the mean value and $\phi^{\prime}$ is the fluctuating component. Initially, isothermal flows will be investigated. Application of the Reynolds decomposition, Eqn. (1), to the Navier-Stokes equations, followed by time-averaging yields the Reynolds-averaged Navier-Stokes (RANS) equations. The dependent variables for the RANS equations are the mean velocity components and pressure, but include a new term which is dubbed the Reynolds stress term. The Reynolds stress can be written as:

$-\overline{\rho u_{i}^{\prime} u_{j}^{\prime}}$ for $\mathrm{i}=1,2,3 ; \mathrm{j}=1,2,3$

where the indices $i$ and $j$ each represent the three spatial coordinates. For a constant density flow, the Reynolds stresses can be written as $-\rho \overline{u_{i}^{\prime} u_{j}^{\prime}}$. The Reynolds stress is a symmetric second rank tensor and, hence, is comprised of only six independent quantities. The shear stresses are given when $\mathrm{i} \neq \mathrm{j}$; the normal stresses are given when $\mathrm{i}=\mathrm{j}$. For essentially two-dimensional flow, there are only three non-zero stresses

of interest, $-\rho \overline{u^{\prime} v^{\prime}},-\rho \overline{u^{\prime 2}}$ and $-\rho \overline{v^{\prime 2}}$. For convenience, the negative sign, the density and the prime notations will be dropped when discussing these stresses. The Reynolds stresses are, in fact, not stresses in the normal sense of the definition. They are called stresses because they are grouped with the shear stresses in the RANS equations for convenience and for modeling purposes. They actually represent the turbulent transport of momentum; that is, the net turbulent transport in the ' $\mathrm{j}$ 'th' direction of the " $\mathrm{i}$ 'th, momentum. In order to be able to solve the RANS equations, the Reynolds stresses must be modeled using a turbulence model. There have been scores of turbulence models developed over the past 150 years or so. None of them has been shown to accurately model turbulent flow for every flow case.

FLUENT offers the user a variety of choices to model or simulate turbulent flow. There are several turbulence models that are used with the Reynolds-averaged Navier-Stokes equations. Some models include a number of additional options that the user can select based on which effects are desired. The RANS turbulence models are:

- $\quad$ the one-equation model of Spalart and Allmaras (wall treatment not required)

- $\quad$ the two-equation $\mathrm{k} \sim \mathcal{\varepsilon}$ model ( $\mathrm{k}=$ turbulent kinetic energy, $\varepsilon=$ dissipation) (requires wall treatment)

- $\quad$ standard model

- $\quad$ realizable model

- $\quad$ renormalization group $(\mathrm{RNG})$ model

- the two-equation $\mathrm{k} \sim \omega$ model of Wilcox $(\omega=\varepsilon / \mathrm{k})$ (wall treatment not required)

- $\quad$ standard model

- $\quad$ shear-stress transport (SST) model 
- $\quad$ the four-equation $\mathrm{v}^{2}-\mathrm{f}$ model of Durbin (wall treatment not required)

- $\quad$ a six-equation Reynolds Stress Model (RSM) (requires wall treatment)

The number of equations mentioned above is the number of differential transport equations that must be solved for the turbulence model. In addition, the user must specify the wall treatment to be used for some of the models plus some other options. The wall treatment determines how the near-wall region is to be handled. Turbulence quantities experience dramatic variations near solid walls and must be carefully handled to achieve any accuracy. Of the three wall treatments available in FLUENT, the first two are wall functions. The standard wall function approach assumes equilibrium between the production and dissipation of turbulent kinetic energy. The second does not assume this equilibrium, but allows the production and dissipation to differ, as may be the case for flows where there is separation and reattachment or severe pressure gradients. Since the flow of Simonin and Barcouda [1986] has strong pressure gradients and shows a small separation behind the tubes, this wall function is investigated. Finally, the third wall treatment is the so-called enhanced wall treatment which solves a low turbulent Reynolds number one-equation turbulence model near the wall to obtain turbulence quantities. This treatment is said to require (FLUENT [2005]) a finer mesh near the wall than for the wall function approach because it is valid into the viscous layer where the turbulent Reynolds number is low. Default options are used for each model except as noted.

The flow configuration of Simonin and Barcouda [1986] (hereafter referred to as S\&B) is of water through a staggered array of tubes $21.7 \mathrm{~mm}$ in diameter, each row spaced $45 \mathrm{~mm}$ apart on tube centers in both the streamwise and lateral directions. The bulk velocity ahead of the tube array is reported to be 1.06 $\mathrm{m} / \mathrm{sec}$. Data are reported for the mean velocities in the streamwise direction, $U$, and the transverse direction, $V$, the normal Reynolds stresses, $\overline{u^{2}}$ and $\overline{v^{2}}$ and the Reynolds shear stress, $\overline{u v}$ for several locations.

A common way to model the Reynolds stresses is the Boussinesq eddy viscosity approach. Here, the Reynolds stresses are assumed to be equal to the turbulent viscosity times the mean rate of strain, i.e.

$-\rho \overline{u_{i} u_{j}}=\mu_{t}\left(\frac{\partial U_{i}}{\partial x_{j}}+\frac{\partial U_{j}}{\partial x_{i}}\right)-\frac{2}{3} \rho k \delta_{i j}, i=1,2,3, \mathrm{j}=1,2,3$

Where $\mu_{\mathrm{t}}$ is the turbulent (eddy) viscosity, $k$ is the turbulent kinetic energy and $\delta_{i j}$ is the Kronecker delta.

The shear stress $\overline{u v}$ is given for $i=1, j=2$. FLUENT [2005] computes the turbulent viscosity, $\mu_{t}$, and the partial derivatives $\partial U / \partial y, \partial V / \partial x$. The shear stress is computed from these components. In this eddy viscosity model, the normal stresses are assumed to be isotropic (equal) and are equal to $2 / 3$ of the turbulent kinetic energy, $\mathrm{k}$, as shown by contracting (setting $\mathrm{i}=\mathrm{j}$ and summing over $\mathrm{i}$ ) Eqn. (3), i.e.

$$
\begin{aligned}
& \left(\overline{u^{2}}+\overline{v^{2}}+\overline{w^{2}}\right)=\frac{\partial U_{i}}{\partial x_{i}}(=0)+\frac{2}{3} k(1+1+1) \text { or } \\
& k=\frac{1}{2}\left(\overline{u^{2}}+\overline{v^{2}}+\overline{w^{2}}\right) \text { or } k=\frac{1}{2}\left(3 \overline{u_{i}^{2}}\right), \text { for } i=1,2 \text { or } 3
\end{aligned}
$$

The term $\partial U_{i} / \partial x_{i}$ is zero because of continuity. All of the RANS models in FLUENT are of the eddy viscosity type except for the Reynolds stress model (RSM) which solves individual transport equations for each turbulent stress. 
Periodic boundary conditions are used for all open flow boundaries as did Benhamadouche and Laurence [2003]. Periodic conditions indicate that the inflow at the left is equal to the outflow to the right. Also, the flow at the top is equal to the flow at the bottom. Hassan and Barsamian [2004], however, use the full depth of the tube bank (for the same data) because they believe that the largest turbulent length scale of the flow is large enough to require it. The mass flow is set at a given value to provide a flow through the flow domain. Although the mean velocity upstream of the tube bundle is reported to be 1.06 $\mathrm{m} / \mathrm{sec}$, the data reported for the mean streamwise velocity do not correspond to this velocity. A B-spline curve was fitted to the mean streamwise velocity data and numerically integrated using the midpoint rule on a fine grid. The data reported by $S \& B$ show a zero value for $U$ at $(x, y)=(0,0.012 \mathrm{~m})$. Actually, the radius of the tube is $0.01085 \mathrm{~m}$. The $\mathrm{B}$-spline curve is set to zero at $0.01085 \mathrm{~m}$, with a sharp increase, which corresponds to the DNS simulations of the same flow shown by Benhamadouche and Laurence [2003]. The mass flow used for the periodic boundary conditions in the streamwise direction is based on the mass flow computed from the numerical integration of the B-spline curve. This value is $40.75 \mathrm{~kg} / \mathrm{sec}$, based on a water density of $998.2 \mathrm{~kg} / \mathrm{m}^{3}$, an area of $(0.045-.0217) \mathrm{m}$ and an average velocity of 1.752 $\mathrm{m} / \mathrm{sec}$. The Reynolds number for the flow based on the computed mass flow and the tube diameter is about 18,000 , much less than for the flow in the VHTR lower plenum $\left(\operatorname{Re}>10^{5}\right)$.

The Statement of Numerical Accuracy published by the ASME Journal of Fluids Engineering [1996] for papers submitted for publication in that journal are used as guidelines for the numerical simulations performed in this study.

Finite volume grids were created for the flow problem using GAMBIT (in FLUENT). Figure 5 illustrates the grids used for various wall treatments and mesh independence studies. The grids are labeled coarsest, coarser, finer and finest. Also shown in Fig. 5a is the coordinate system. Although the coarsest grid looks finer than the coarser grid, the former is coarser near the tube walls than the latter. The FLUENT manual recommends that the dimensionless distance from the wall $\mathrm{y}^{+}\left(\equiv \mathrm{u}_{\tau} \mathrm{y} / v, \mathrm{u}_{\tau}=\left[\tau_{\mathrm{w}} / \rho\right]^{1 / 2}\right.$, where $\tau_{\mathrm{w}}$ is the wall shear stress) to the middle of the first cell be greater than about 30 . Figure 6 plots the $\mathrm{y}^{+}$values for all of the five walls in the flow domain for the coarser and finer grids. The quarter tube walls are labeled as 'wall1,' 'wall2,' to 'wall4' starting in the lower left corner of the grid and moving clockwise. Wall 'wallcen' is the center tube. As shown, the $\mathrm{y}^{+}$values vary from about 1 to 25 for the coarser grid. Actually, the wall functions are designed to be useable for all ranges of $\mathrm{y}^{+}$. The FLUENT manual recommends that $\mathrm{y}^{+}$values for the enhanced wall treatment be $1 \leq \mathrm{y}^{+} \leq 5$. As shown, the wall values are mostly within this range. Values of $\mathrm{y}^{+}$for the coarsest grid are mostly above 30 .

An iterative convergence study was performed using the Reynolds stress model (RSM) using standard wall functions in FLUENT. The default options for the RSM are used except that the turbulent kinetic energy equation is not used to compute $\mathrm{k}$ near the wall. However, $\mathrm{k}$ can simply be computed from its definition from the three normal Reynolds stresses, which are already computed. Computing $\mathrm{k}$ from another equation seems to be incompatible with the RSM and indeed prevents full convergence of the model (to $1 \times 10^{-6}$ tolerance). The QUICK scheme is used for convective differencing for all simulations.

The solution tolerance was set to values of $1 \times 10^{-3}, 1 \times 10^{-4}, 1 \times 10^{-5}$ and $1 \times 10^{-6}$ for every equation and solutions computed. Figure 7 compares the computed solutions against the S\&B data for the mean streamwise and transverse velocities ( $\mathrm{U} \& \mathrm{~V}$, respectively) and the Reynolds transverse normal and shear stresses $\left(\overline{v^{2}} \& \overline{u v}\right.$, respectively) for the four levels of tolerance. As can be seen, the tolerances of $1 \times 10^{-3}$ and $1 \times 10^{-4}$ are not converged, even though the results for the tolerance of $1 \times 10^{-4}$ provides very good agreement with the data for $\mathrm{U}$ and $\overline{v^{2}}$. The change from $1 \times 10^{-5}$ to $1 \times 10^{-6}$ is at most a few percent and may be adequate. However, convergence to the tightest tolerance of $1 \times 10^{-6}$ is desired and is used as the target tolerance. Results that are obtained for a higher tolerance will be so noted. In contrast, the default tolerance is set to $1 \times 10^{-3}$, while the FLUENT manual suggests that a tolerance of $1 \times 10^{-4}$ may be needed. 


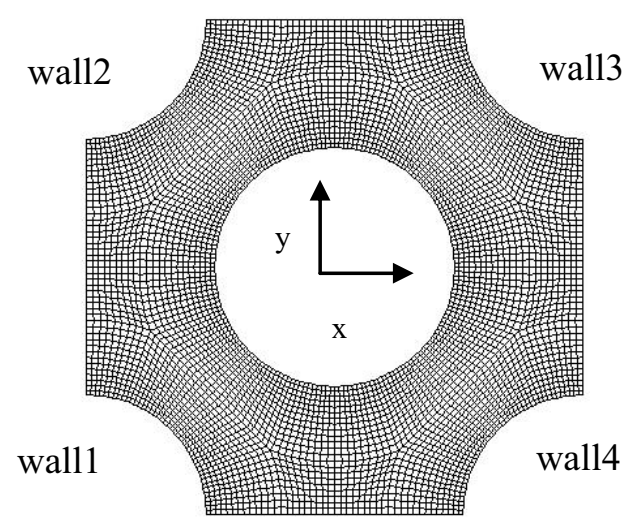

(a)

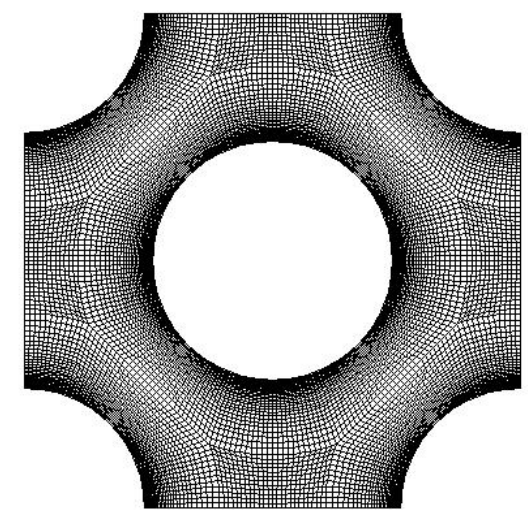

(c)

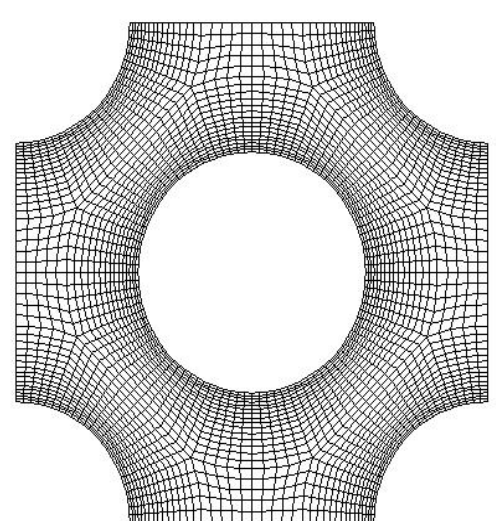

(b)

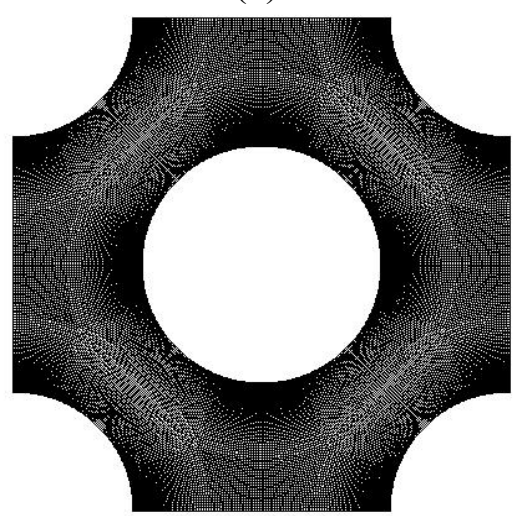

(d)

Figure 5. Finite volume grids for the tube bundle simulations (a) coarsest, (b) coarser, (c) finer and (d) finest. The coordinate system is shown.

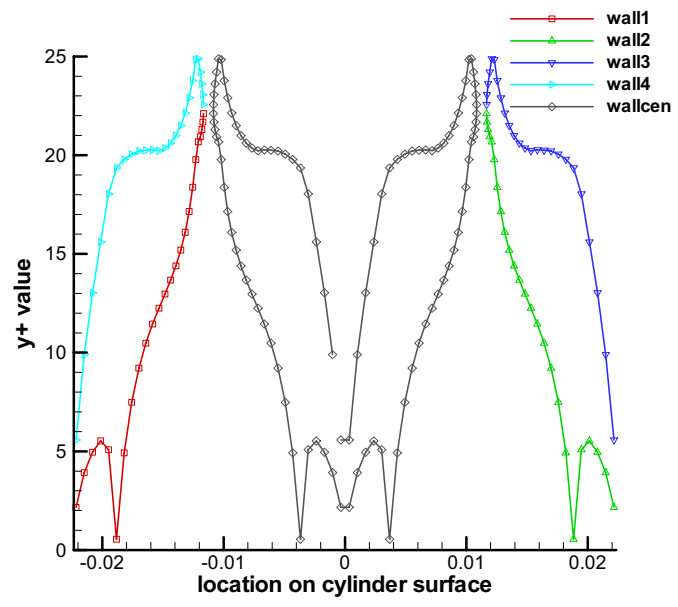

(a)

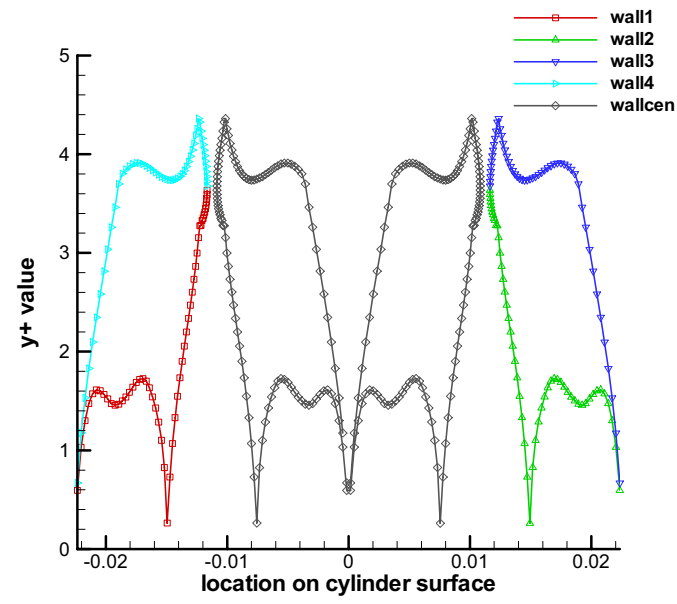

(b)

Figure $6 \cdot \mathrm{y}^{+}\left(\equiv \mathrm{u}_{\tau} \mathrm{y} / \mathrm{v}\right)$ distribution for the (a) coarser grid and (b) the finer grid. 


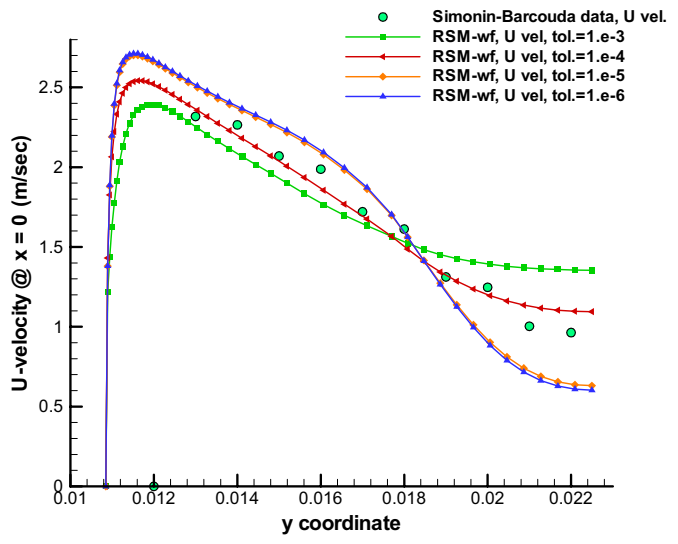

(a)

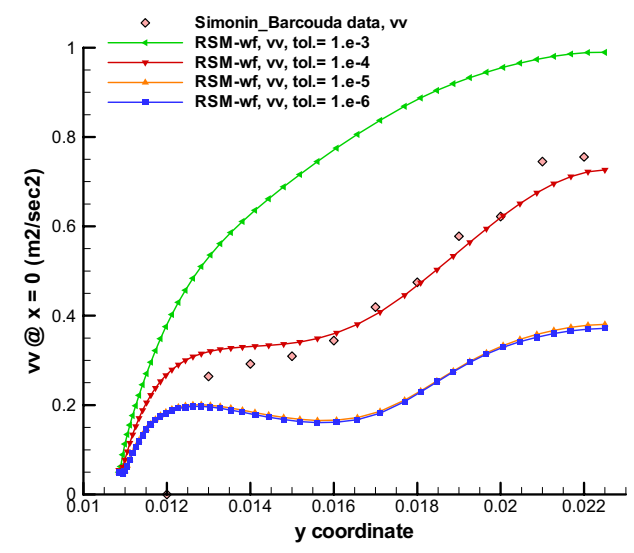

(c)

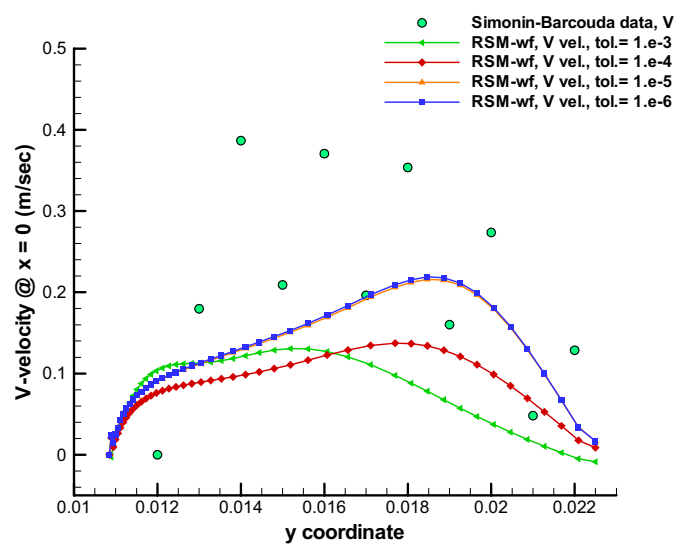

(b)

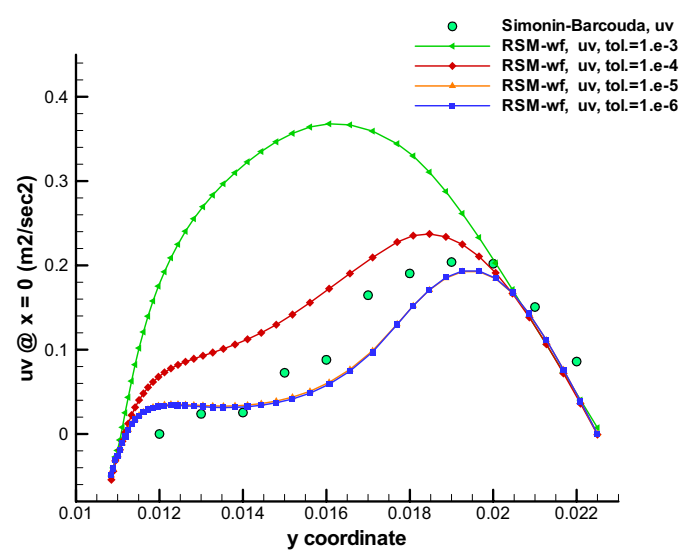

(d)

Figure 7. Comparison of solutions for iterative tolerances of $1 \times 10^{-3}$ to $1 \times 10^{-6}$ for (a) the mean streamwise velocity $\mathrm{U}$, (b) the mean transverse velocity $\mathrm{V}$, (c) the transverse normal stress $\overline{v^{2}}$ and (d) and the shear stress $\overline{u v}$.

Figure 8 illustrates the results for $\mathrm{U}$ and $\mathrm{V}$ velocities compared to the (de-normalized) data of $\mathrm{S} \& \mathrm{~B}$ for the three wall treatments: standard and nonequilibrium wall functions and the enhanced wall treatment. In addition, Figure 8a illustrates the B-spline curve fitted to U. The results for the two wall function cases are very close, indicating that the flow is close to equilibrium, while those for the enhanced wall treatment are significantly better. According to D. Laurence [2005], the data include measurements from both above and below the center tube, with mirrored bottom data superimposed on the top. For V, Fig. 8b, the variation is quite large. However, DNS and LES calculations reported in Benhamadouche and Laurence [2003] indicate that the lower-value data for $\mathrm{V}$ are more correct. The spike in the predictions for the $\mathrm{V}$ velocity in Fig. $8 \mathrm{~b}$ near the cylinder wall $(\mathrm{y}=0.01085 \mathrm{~m})$ is likely due to the fact that mean and turbulence quantities are computed by a given wall treatment adjacent to the wall, which may or may not transition smoothly to the values computed by the transport equations employed farther from the wall. While not perfect, the results for the $\mathrm{k} \sim \varepsilon$ model using the enhanced wall treatment show the best agreement. 


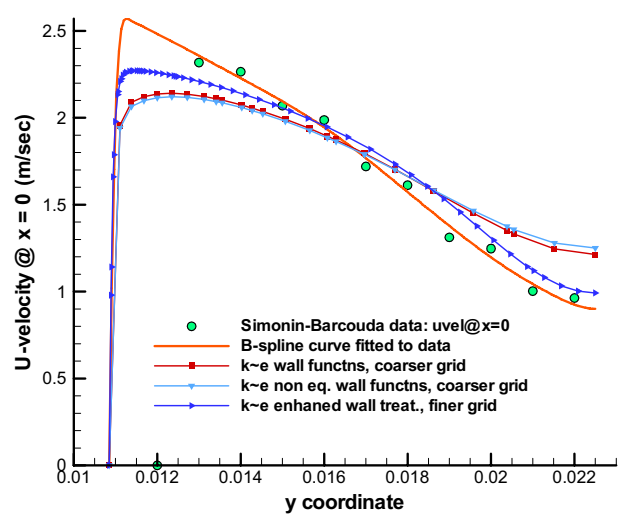

(a)

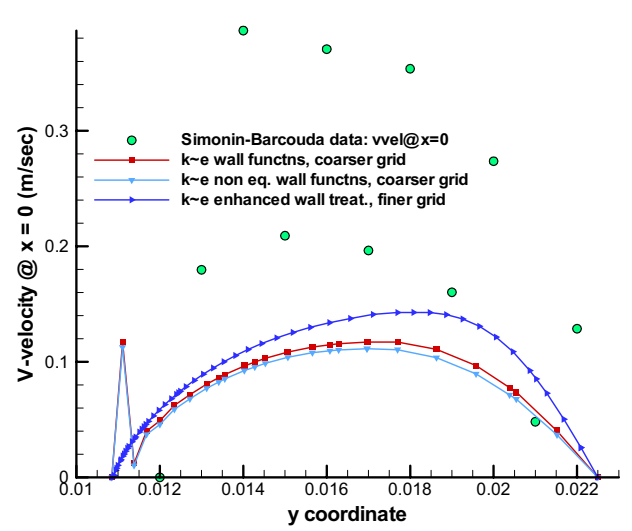

(b)

Figure 8. Results for (a) $\mathrm{U}$ and (b) $\mathrm{V}$ for the $\mathrm{k} \sim \varepsilon$ model for standard and nonequilibrium wall functions and the enhanced wall treatment compared to the data of S\&B.

Figure 9 illustrates the effect of the grid on the predictions for the standard $k \sim \varepsilon$ model using the standard wall functions at $\mathrm{x}=0$. For the coarsest grid, most of the $\mathrm{y}^{+}$values are greater than 30 as recommended by the FLUENT manual. The results for the coarser and coarsest grid are about the same, but are poorer than for the finer grid. The finest grid was also used to check for grid independence. For the realizable $\mathrm{k} \sim \varepsilon$ model, a maximum difference of $4.9 \%$ was computed for the mean streamwise velocity. The finer grid is subsequently used except as noted below.

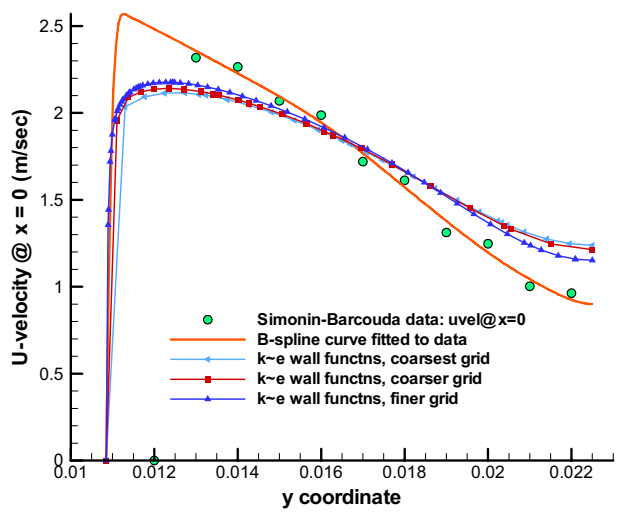

(a)

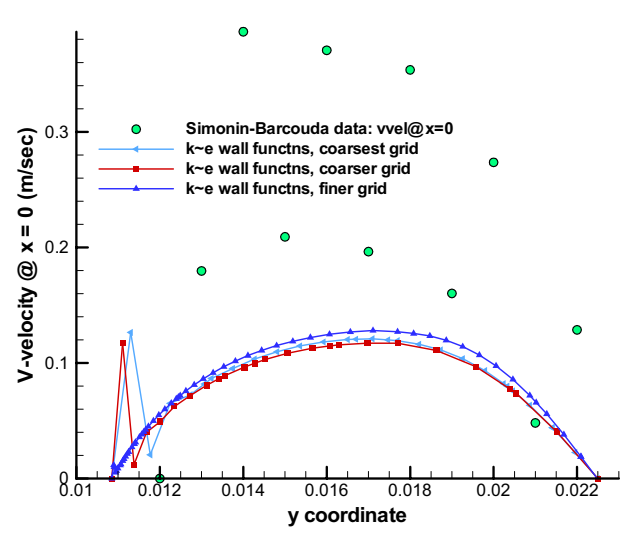

(b)

Figure 9. Results for the mean (a) streamwise and (b) transverse velocities for the standard $\mathrm{k} \sim \varepsilon$ turbulence model using standard wall functions for three different grids at $\mathrm{x}=0$.

Figure 10 compares predictions of normal and shear Reynolds stresses at $\mathrm{x}=0$. The $\mathrm{k} \sim \varepsilon$ model equates the normal stresses, though they clearly are not equal for this flow as shown by Figure 10a. The shear stresses shown in Figure 10b are computed as described above. There is no clear approach that is superior for the transverse normal or shear Reynolds stresses. The results for the enhanced wall treatment are best for $\overline{u^{2}}$. 


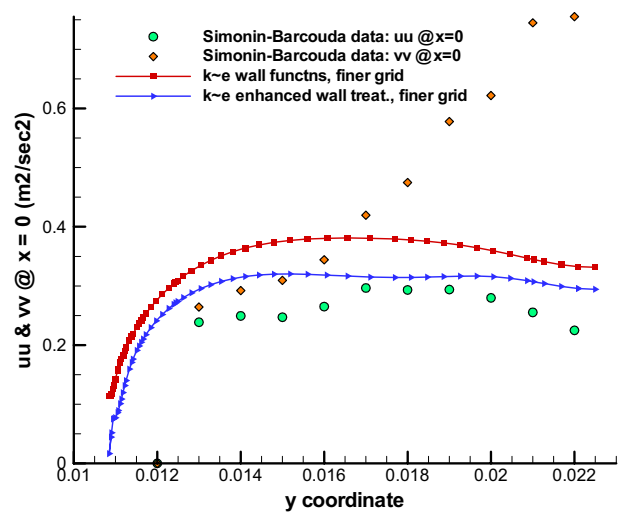

(a)

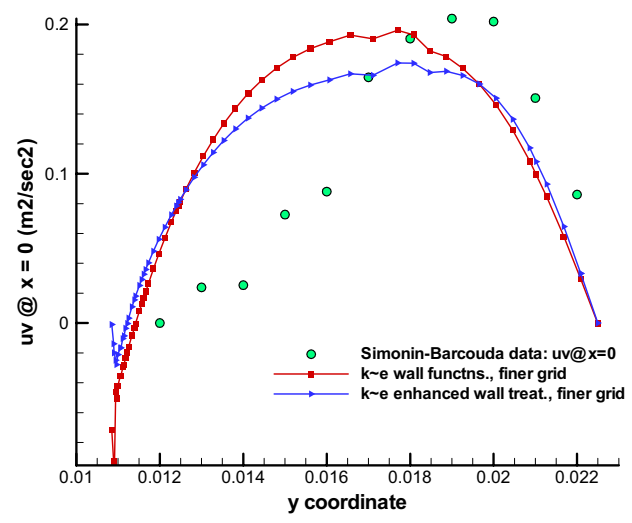

(b)

Figure 10. Simulations for the (a) normal and (b) shear Reynolds stresses for the $\mathrm{k} \sim \varepsilon$ model employing standard wall functions and the enhanced wall treatment.

Figure 11 compares simulations of the mean streamwise and transverse velocities with the data of $\mathrm{S} \& \mathrm{~B}$ at $\mathrm{x}=0.011 \mathrm{~m}$ for standard wall functions and the enhanced wall treatment. While results for the two wall treatments are different, the data do not support a conclusion that one is clearly superior.

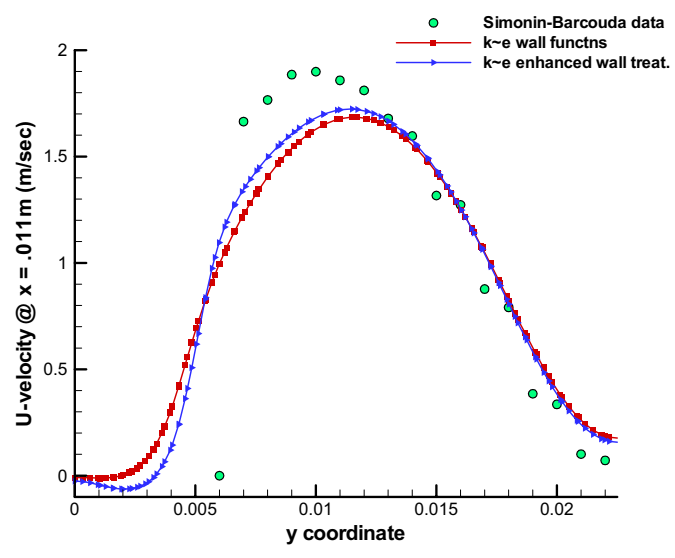

(a)

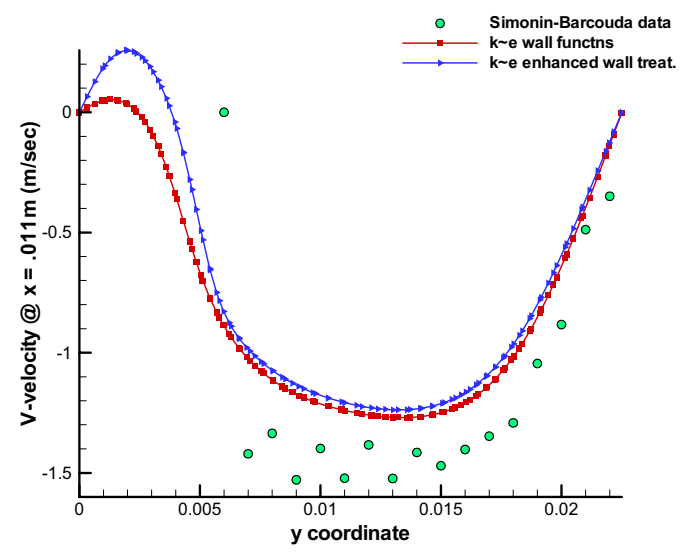

(b)

Figure 11. Comparisons of mean (a) streamwise and (b) transverse velocities at $\mathrm{x}=0.011 \mathrm{~m}$ with $\mathrm{S} \& \mathrm{~B}$ data for the standard wall functions and the enhanced wall treatment.

Figure 12 compares the results for the normal and shear Reynolds stresses for the same two wall treatments. While the results for the enhanced wall treatment are somewhat better than for the standard wall functions, neither is satisfactory. 




(a)



(b)

Figure 12. Comparisons of (a) normal and (b) shear Reynolds stresses at $\mathrm{x}=0.011 \mathrm{~m}$ with S\&B data for the standard wall functions and the enhanced wall treatment.

FLUENT provides the standard $\mathrm{k} \sim \varepsilon$ model plus two other versions. A version based on renormalization group (RNG) theory is provided plus a version called the realizable $\mathrm{k} \sim \varepsilon$ model. The realizable model is designed to prevent negative turbulence intensities at high strain rates. Simulations with these two $\mathrm{k} \sim \varepsilon$ model variations are performed with the enhanced wall treatment. Figure 13 compares $U$ and $V$ at $\mathrm{x}=0$ for the standard, RNG and realizable $\mathrm{k} \sim \varepsilon$ models.

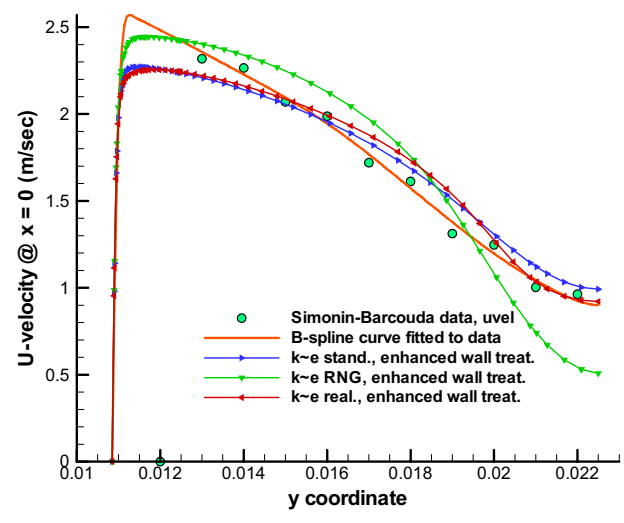

(a)

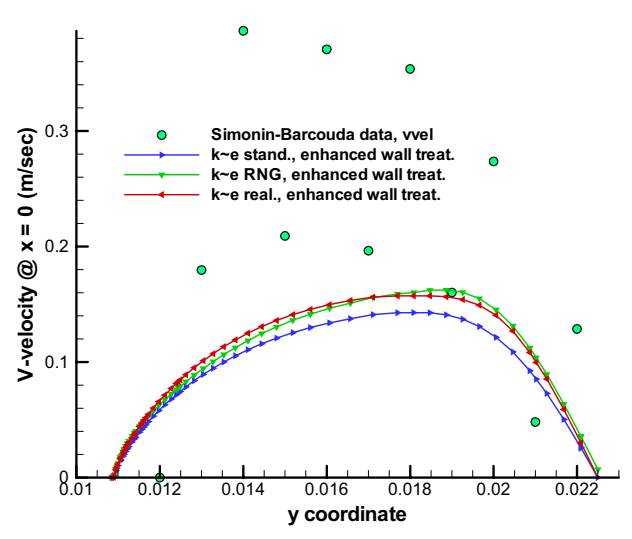

(b)

Figure 13. Mean (a) $\mathrm{U}$ and (b) $\mathrm{V}$ velocities at $\mathrm{x}=0$ for the standard, $\mathrm{RNG}$ and realizable $\mathrm{k} \sim \varepsilon$ models all employing the enhanced wall treatment compared to the $\mathrm{S} \& \mathrm{~B}$ data.

The standard $\mathrm{k} \sim \varepsilon$ model shows the least amount of curvature for the mean streamwise velocity of the three, in accord with the data, though the RNG model is better near the cylinder wall. None of the simulations for the transverse velocity are satisfactory. Figure 14 compares the S\&B data with the same three $\mathrm{k} \sim \varepsilon$ models using the enhanced wall treatment for the normal and shear Reynolds stresses. 


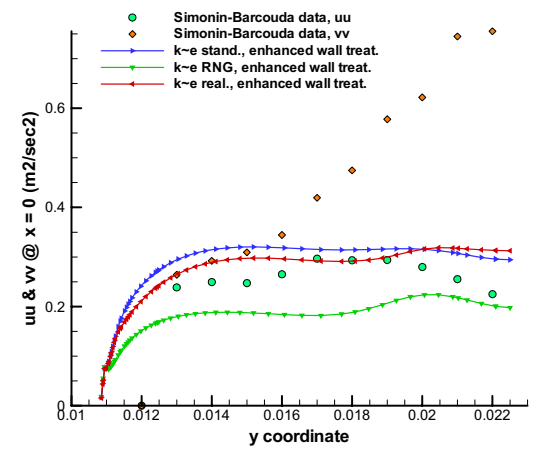

(a)

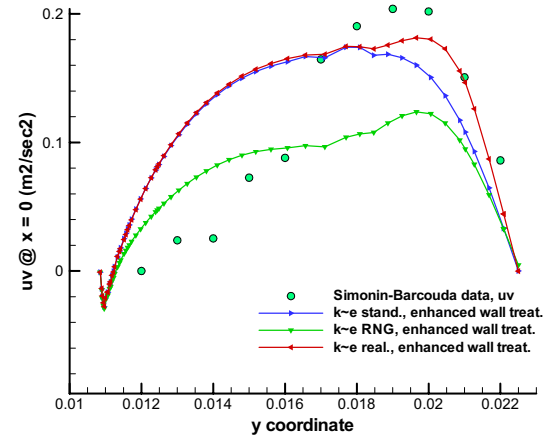

(b)

Figure 14. Comparisons with the S\&B data for the (a) normal and (b) shear stresses for the standard, $\mathrm{RNG}$ and realizable $\mathrm{k} \sim \varepsilon$ models, all using the enhanced wall treatment.

The results for the standard and realizable models are best for the normal stress and the shear stress compared against the RNG model. The realizable $\mathrm{k} \sim \varepsilon$ model has a slight edge among the three versions for best accuracy based on Figures 13 and 14. The variation in the data, particularly for the mean transverse velocity, and the difference between the reported mass flow rate and that computed from the mean streamwise velocity casts some doubt on the accuracy of the data.

Figure 15 compares the $\mathrm{S} \& \mathrm{~B}$ data with mean velocity results for the realizable $\mathrm{k} \sim \varepsilon$ model using the enhanced wall treatment, the $\mathrm{k} \sim \omega$ model employing shear stress transport (SST) (both for the fine grid) and the Reynolds stress model (RSM) using standard wall functions for both the fine and coarsest grid at $\mathrm{x}=0$. It must be noted that the $\mathrm{k} \sim \omega$ model with SST did not converge below $7.25 \times 10^{-5}$; the RSM model with default options using wall functions converged to $5.6 \times 10^{-5}$ and $1.0 \times 10^{-5}$ for the fine and coarsest grid, respectively. Additional iterations caused the residuals to climb. The realizable $\mathrm{k} \sim \varepsilon$ model converged to $1.15 \times 10^{-6}$. Other versions of these models (the Spalart-Allmaras model, the standard $\mathrm{k} \sim \omega$ model and the RSM with enhanced wall treatment) would not converge to $1.0 \times 10^{-4}$ and are not reported.

The RSM results for the coarsest mesh are seen to mimic the data quite well for U (Fig. 15a), although the RSM results for the fine grid display the correct trend of a flatter profile for $\mathrm{x}<0.017$. However, the results for the coarsest mesh for V (Fig. 15b) are very poor, while the RSM results on the fine grid are better than the others.

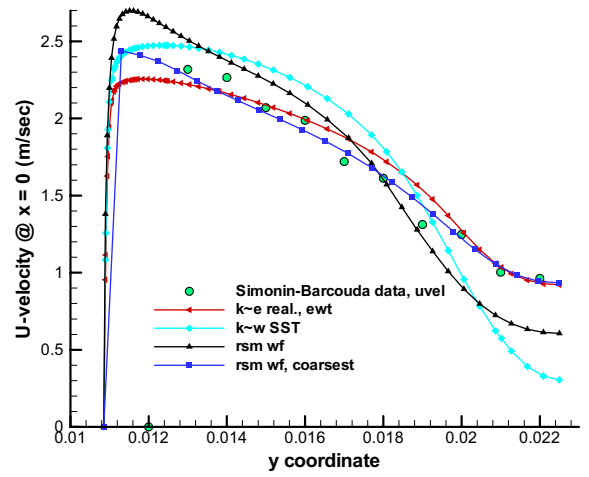

(a)

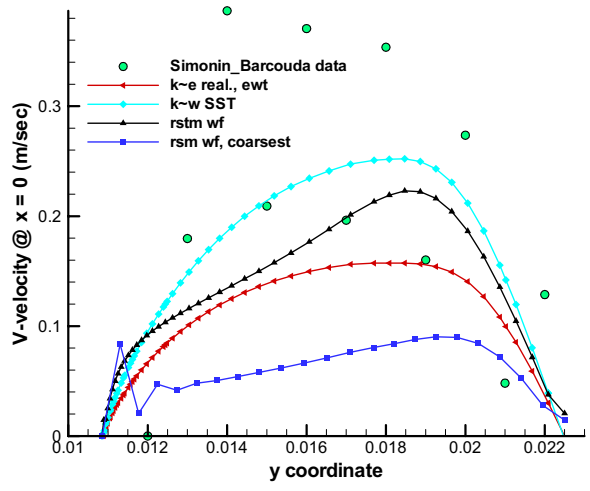

(b)

Figure 15. Results for mean (a) $\mathrm{U}$ and (b) $\mathrm{V}$ velocities for the realizable $\mathrm{k} \sim \varepsilon$ model using the enhanced wall treatment, the $\mathrm{k} \sim \omega$ model using shear stress transport (SST) and the Reynolds Stress Model (RSM) using wall functions for fine and coarsest grids at $\mathrm{x}=0$. 
The quantity $\omega$ in the $\mathrm{k} \sim \omega$ model is termed the specific dissipation rate and is essentially $\varepsilon / \mathrm{k}$. The $\mathrm{k} \sim \varepsilon$ and $\mathrm{k} \sim \omega$ models all assume that the normal Reynolds stresses are equal $\left(\overline{u^{2}}=\overline{v^{2}}=\overline{w^{2}}\right)$. Differential transport equations are derived for the Reynolds stresses in the RSM; that is, the Reynolds stresses are found by solving differential transport equations. Four Reynolds stresses are solved for a 2D problem, the three normal stresses and the shear stress $\overline{u v}$.

Figure 16 compares the results for the normal stresses $\overline{u^{2}}$ and $\overline{v^{2}}$ and the shear stress $\overline{u v}$ for the realizable $\mathrm{k} \sim \varepsilon$ model with enhanced wall treatment, the $\mathrm{k} \sim \omega$ model with SST and the RSM using standard wall functions for the fine and coarsest meshes with the S\&B data at $\mathrm{x}=0$.

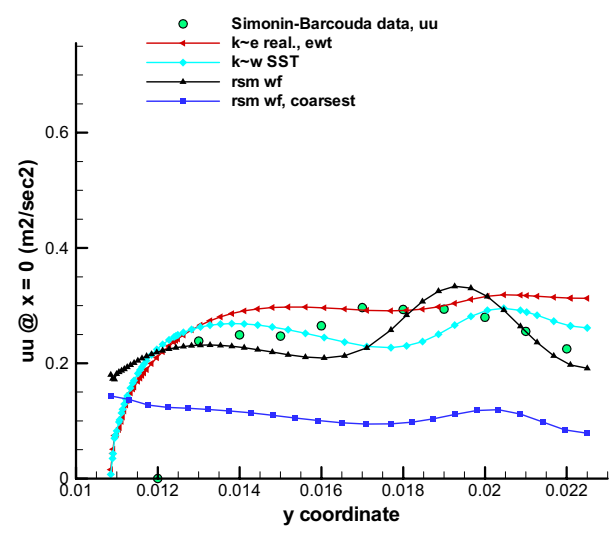

(a)



(b)

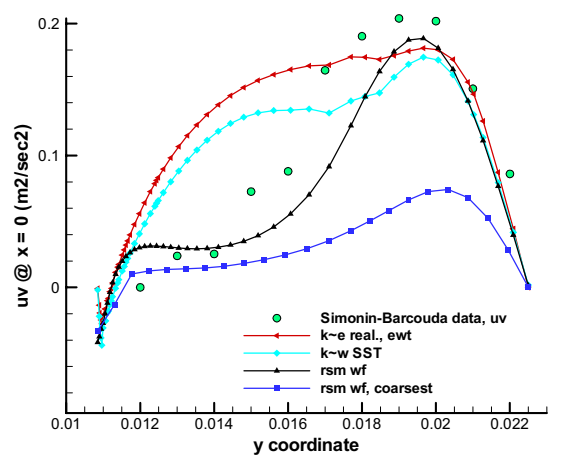

(c)

Figure 16. Results for (a) $\overline{u^{2}}$ and (b) $\overline{v^{2}}$ stresses and (c) the shear stress $\overline{u v}$ for the realizable $\mathrm{k} \sim \varepsilon$ model using the enhanced wall treatment, the $\mathrm{k} \sim \omega$ model using shear stress transport and the RSM using wall functions for the fine and coarsest grids at $\mathrm{x}=0$.

The finer grid RSM results quite neatly capture the data for the $\overline{u^{2}}$ and $\overline{u v}$ stresses; they also show the correct trend for the $\overline{v^{2}}$ data, though not the correct quantitative values. In summary, the RSM with standard wall functions using the fine grid yields the best results for the data at $\mathrm{x}=0$.

To provide additional comparison information, the results are compared to the data for $\mathrm{x}=11 \mathrm{~mm}$. Figure 17 compares the same turbulence models with the $\mathrm{S} \& \mathrm{~B}$ data at $\mathrm{x}=11 \mathrm{~mm}$ for the mean streamwise and transverse velocities. 


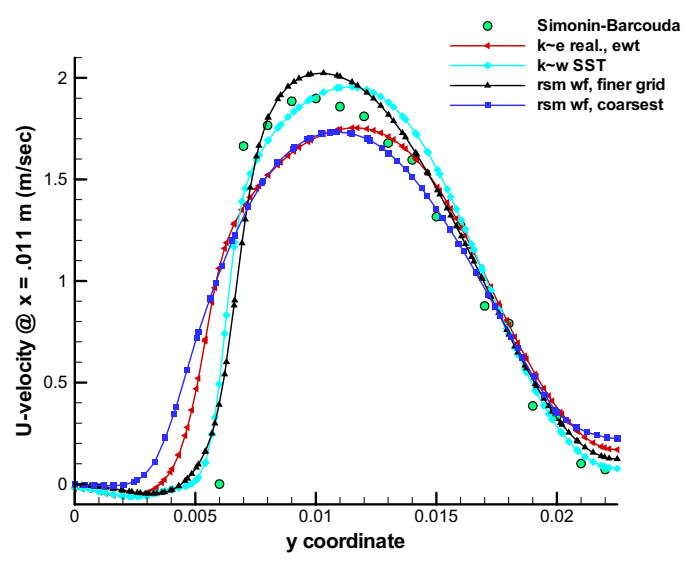

(a)

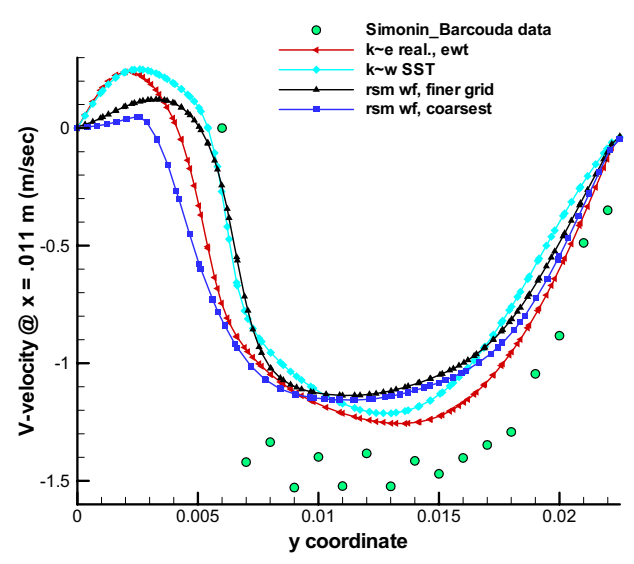

(b)

Figure 17. Results for mean (a) $\mathrm{U}$ and (b) $\mathrm{V}$ velocities for the realizable $\mathrm{k} \sim \varepsilon$ model using the enhanced wall treatment, the $\mathrm{k} \sim \omega$ model using shear stress transport (SST) and the RSM using wall functions for the finer and coarsest grids at $\mathrm{x}=11 \mathrm{~mm}$.

The $\mathrm{k} \sim \omega$ model and the RSM on the finer grid capture the steep rise shown by the data for $U$ (Fig. 12a), though the RSM shows a more correct qualitative trend than the others. The results for the mean transverse velocity $\mathrm{V}$ (Fig. 12b) are all quite close with the realizable $\mathrm{k} \sim \varepsilon$ model dipping the lowest at the minimum.

Figure 18 compares results for the four models for the three Reynolds stresses as above for $\mathrm{x}=11$ $\mathrm{mm}$. All of the results show the correct trend for the $\overline{u^{2}}$ stress, while all of them get it wrong for the $\overline{v^{2}}$ stress. The coarse grid RSM has the best quantitative results for the former stress, while the fine grid RSM does the best for the latter stress. All results show the correct trend for the shear stress (Fig. 18c), while the coarsest grid RSM is best qualitatively.

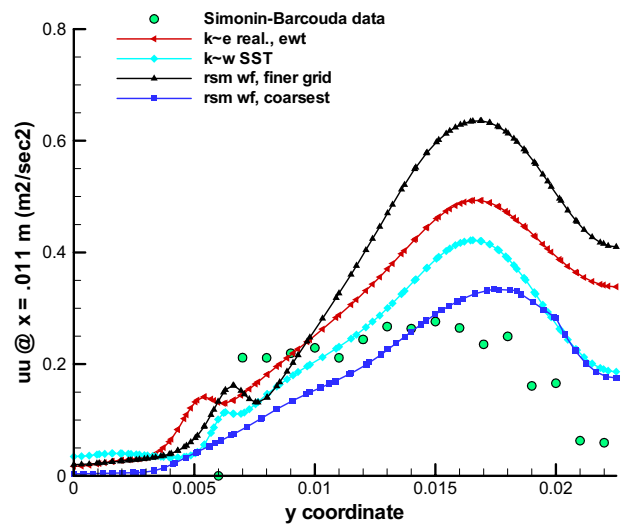

(a)

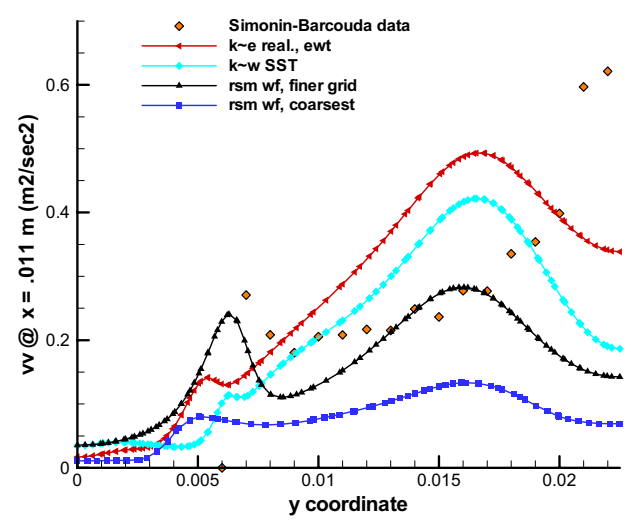

(b) 




(c)

Figure 18. Results for (a) $\overline{u^{2}}$ and (b) $\overline{v^{2}}$ and (c) the shear stress $\overline{u v}$ for the realizable $\mathrm{k} \sim \varepsilon$ model using the enhanced wall treatment, the $\mathrm{k} \sim \omega$ model using shear stress transport and the RSM using wall functions for the finer and coarsest grids for $\mathrm{x}=11 \mathrm{~mm}$.

Calculations have been made for the RSM with the option to solve an extra transport equation for turbulence kinetic energy $\mathrm{k}$ for use with boundary conditions turned off. Convergence to $1 \times 10^{-6}$ was obtained. Also calculations using the $v^{2}$-f model of Durbin, FLUENT [2005] have been made, also to a convergence of $1 \times 10^{-6}$. The $v^{2}$-f model solves an additional transport equation for $\overline{v^{2}}$, even though the value of $\overline{v^{2}}$ is given by the Boussinesq model, Eqn. (1). However, $\overline{v^{2}}$ is used as the velocity scale in the specification of the turbulent viscosity. Hence, there are two distributions obtained for $\overline{v^{2}}$, one from the solution of the additional transport equation for $\overline{v^{2}}$, and one from the Boussinesq model. Figure 19 illustrates mean velocity results at $\mathrm{x}=0$ for the RSM (no $\mathrm{k}$ ), the $\mathrm{v}^{2}-\mathrm{f}$ model and the realizable $\mathrm{k} \sim \varepsilon$ model.



(a)

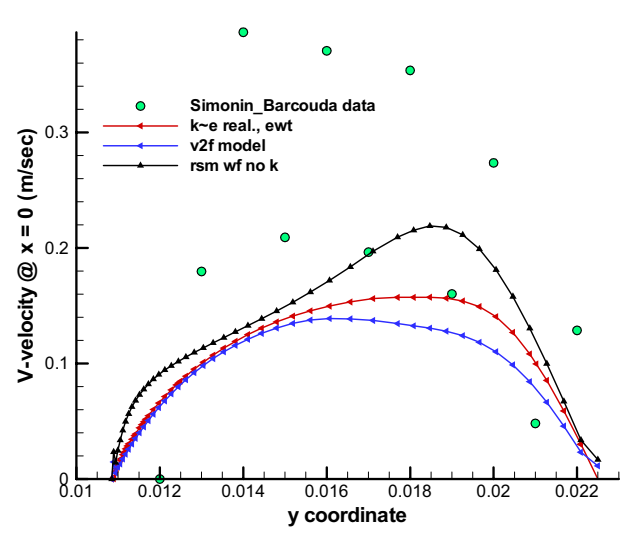

(b)

Figure 19. Mean velocity profiles at $\mathrm{x}=0$ for realizable $\mathrm{k} \sim \varepsilon, \mathrm{v}^{2}-\mathrm{f}$ and RSM (no $\mathrm{k}$ option) models.

Figure 20 shows profiles for the three Reynolds stresses for the realizable $\mathrm{k} \sim \varepsilon$ model using the enhanced wall treatment and the Reynolds Stress Model using wall functions, but no extra equation for k, all on the finer grid. From Figure $20 \mathrm{~b}$, we see that the profile based on the transport equation for $\overline{v^{2}}$ does not match the profile computed by the Boussinesq model. We also see that the $\mathrm{v}^{2}-\mathrm{f}$ model is overall poorer than the realizable model, which, in turn, is poorer that the RSM in matching the data. 


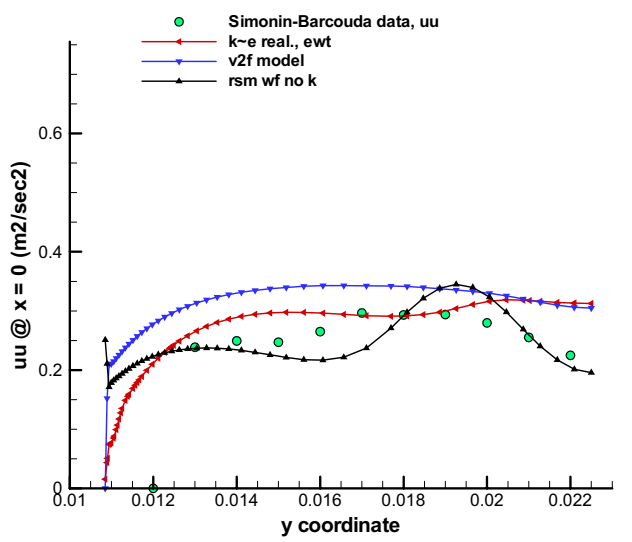

(a)

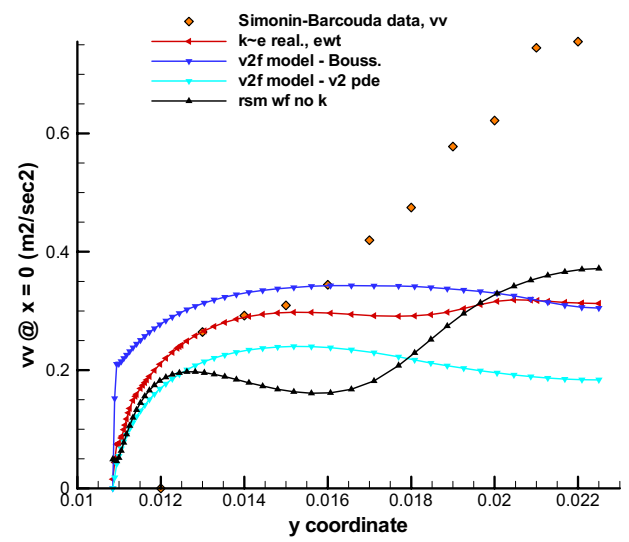

(b)

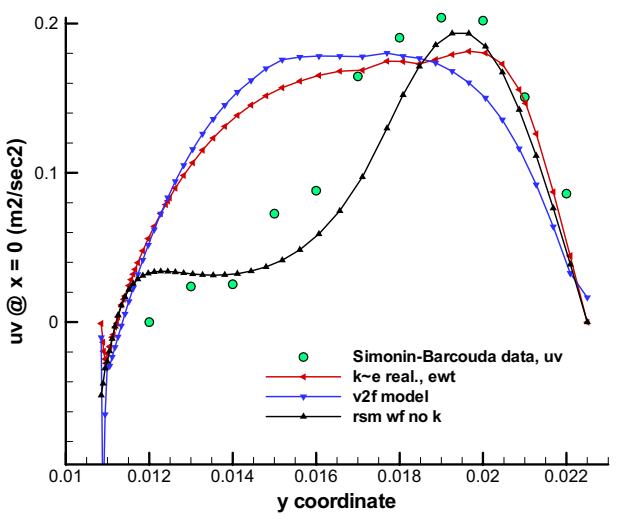

(c)

Figure 20. Results for (a) $\overline{u^{2}}$ and (b) $\overline{v^{2}}$ normal stresses and (c) the shear stress $\overline{u v}$ for the realizable $\mathrm{k} \sim \varepsilon$ model using the enhanced wall treatment, the $v^{2}-f$ model and the RSM using wall functions, but no extra equation for $\mathrm{k}$, all on the finer grid at $\mathrm{x}=0$.

Preliminary results have been obtained using detached eddy simulation (DES) employing the default options in FLUENT. DES is a hybrid approach that uses large eddy simulation (LES) far from the walls and the unsteady one-equation model of Spalart and Allmaras near the walls, FLUENT [2005]. LES computes the turbulence directly for eddies larger than the grid size, but uses a sub-grid scale model for the smaller turbulence eddies; it is an unsteady 3D approach. Figure 21 illustrates the 3D grid used for DES superimposed on the results for the mean streamwise velocity at time 2.828 secs. As can be seen, the variation in the $\mathrm{z}$-direction is relatively small, indicating a $2 \mathrm{D}$ flow. 

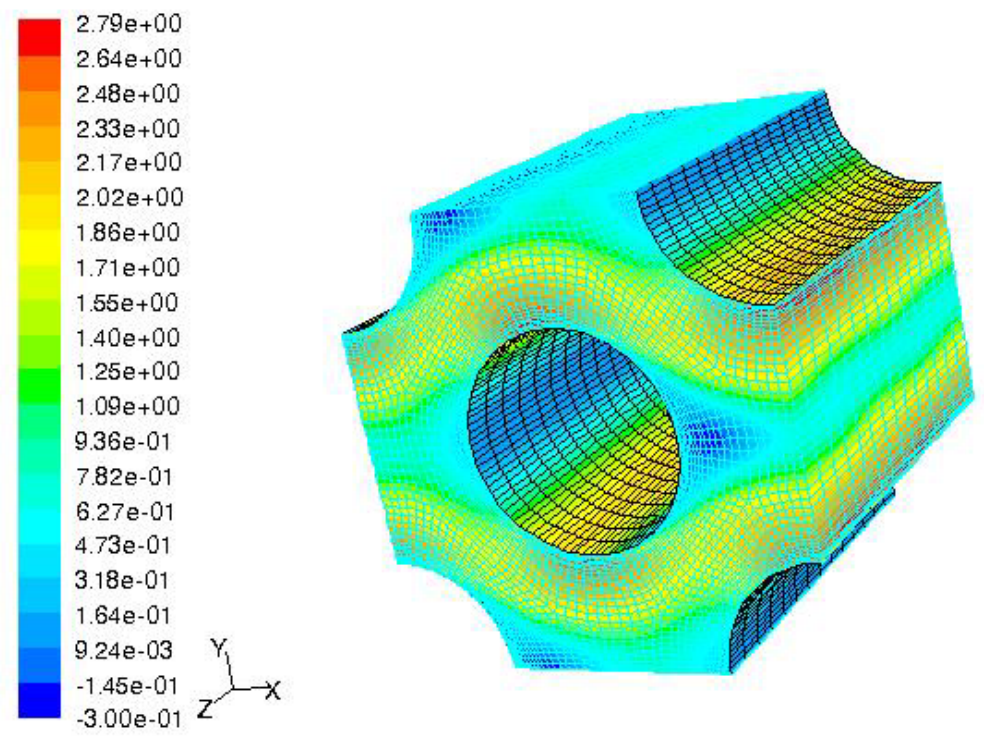

Figure 21. Contours for the mean streamwise velocity $U(\mathrm{~m} / \mathrm{sec})$ at time 2.828 seconds using detached eddy simulation (DES).

Figure 22 shows results for the mean streamwise and transverse velocities compared to the data of $\mathrm{S} \& \mathrm{~B}$, the realizable $\mathrm{k} \sim \varepsilon$ model and the RSM using wall functions at time 2.828 seconds. The spike in the $\mathrm{V}$-velocity near the cylinder wall $(\mathrm{y}=0.01085 \mathrm{~m})$ is probably due to the coarseness of the near-wall grid spacing applied for the DES simulations. Figure 23 illustrates the squared RMS values for the streamwise and transverse velocities compared to the streamwise and transverse normal stresses.

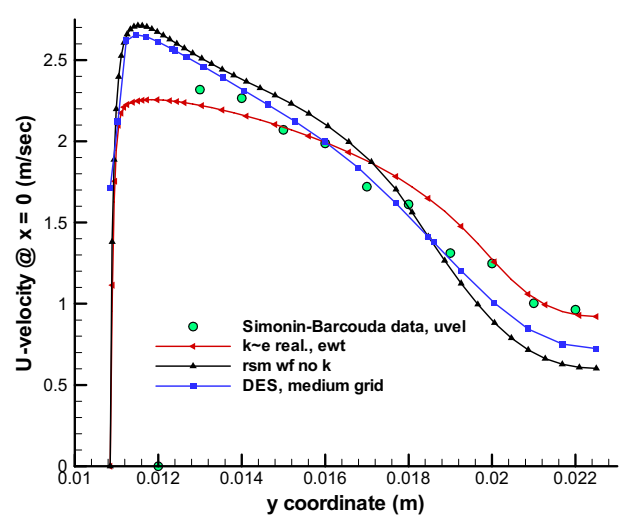

(a)

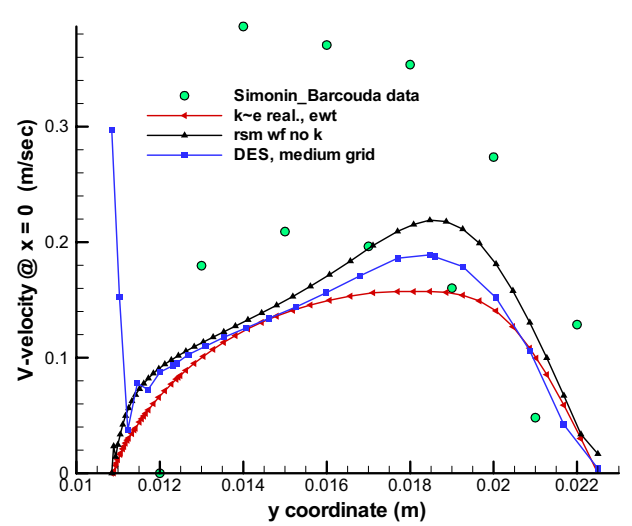

(b)

Figure 22. Results for DES for the (a) mean streamwise and (b) transverse velocities compared to the data of $\mathrm{S} \& \mathrm{~B}$ and other results. 


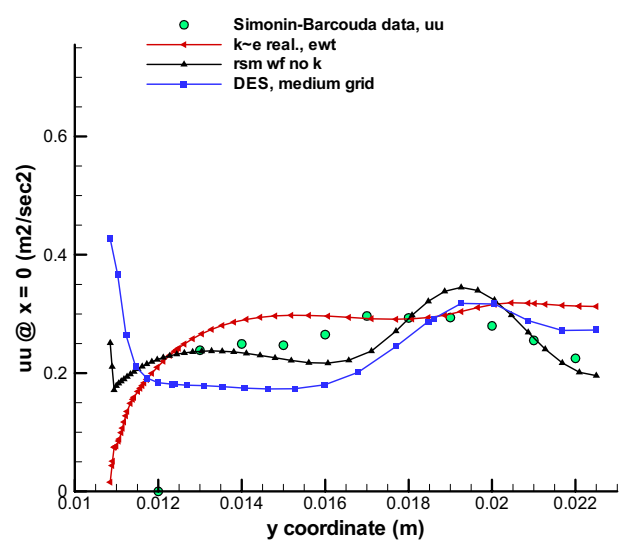

(a)

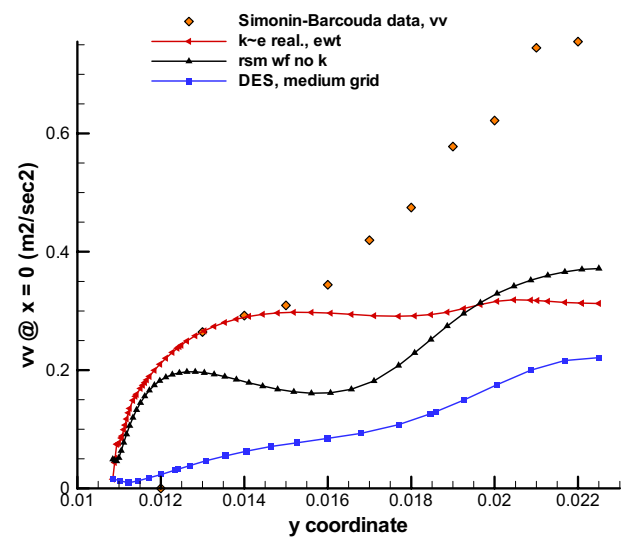

(b)

Figure 23. Results for DES for Reynolds stresses (a) $\overline{u^{2}}$ and (b) $\overline{v^{2}}$ compared to the S\&B data and results for the realizable $\mathrm{k} \sim \mathcal{\varepsilon}$ and RSM models.

Additional DES simulations were made. These used the results of Figures 22, 23 as the starting point. The time step used was set to $5.0 \times 10^{-5}$ and results for three spanwise locations, $\mathrm{z}=0.25,0.5$ and 0.75 of the total depth $(\mathrm{z}=0.0434 \mathrm{~m})$ which is four times the radius of the tubes. Results are compared to the RSM results also shown in Figures 22, 23. Figures 24 and 25 illustrate results for the mean streamwise and transverse velocities and the normal Reynolds stresses, $\overline{u^{2}}$ and $\overline{v^{2}}$ for $\mathrm{x}=0$ at time $\mathrm{t}=$ 3.5713 seconds.

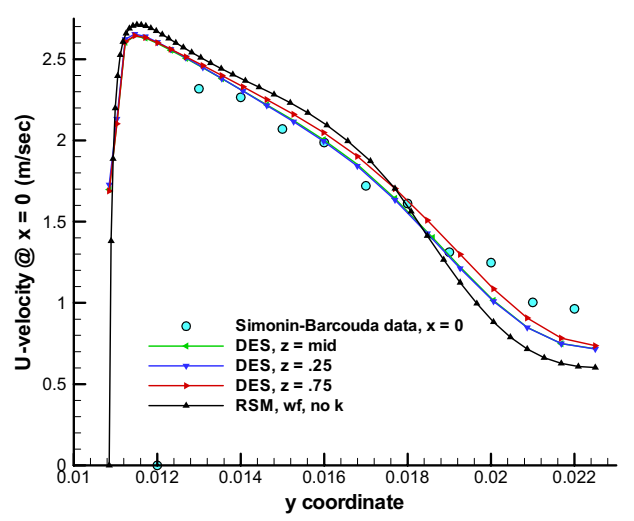

(a)

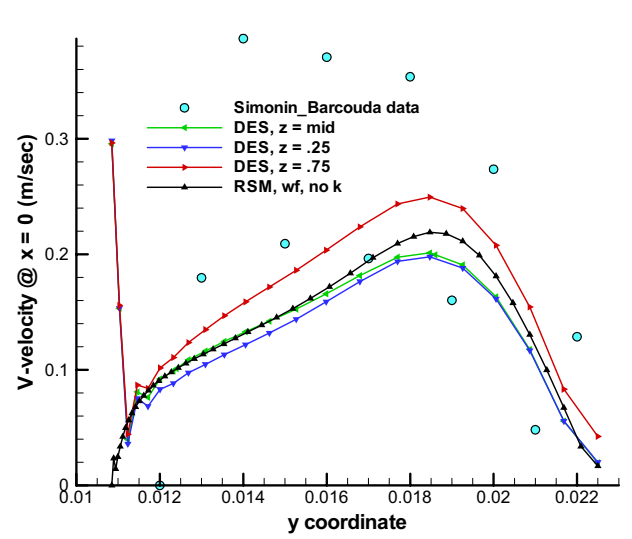

(b)

Figure 24. Results for DES for the mean velocities at $1 / 4,1 / 2$ and $3 / 4$ of the depth of the gird compared to RSM results and the S\&B data. 


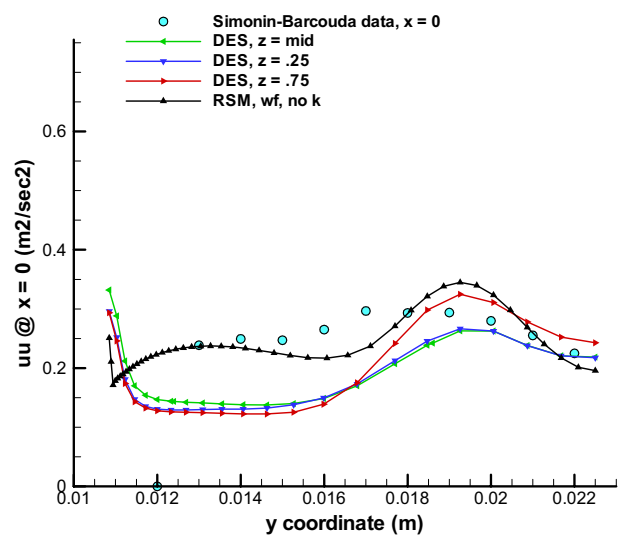

(a)

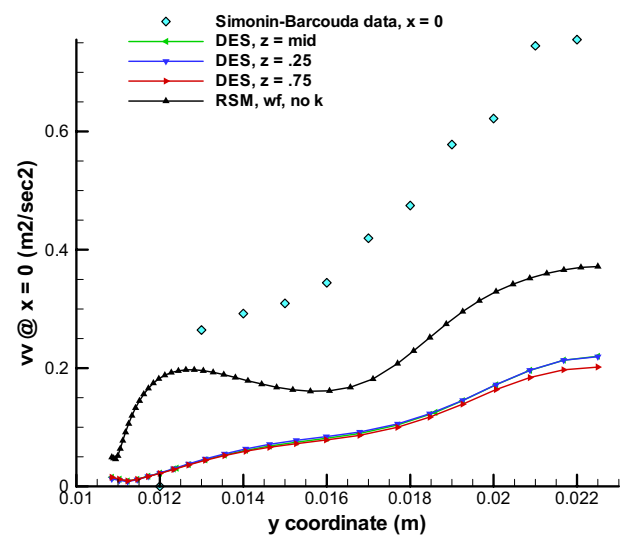

(b)

Figure 25. Results for DES for the normal Reynolds stresses $\overline{u^{2}}$ and $\overline{v^{2}}$ at $1 / 4,1 / 2$ and $3 / 4$ of the depth of the grid compared to RSM results and the S\&B data.

As can be seen in Figures 24 and 25, the computations for the DES results are not satisfactory because the values for $z=1 / 4,1 / 2$, and $3 / 4$ should be the same. The reason may be that a longer time is required or that the grid in the spanwise direction $\mathrm{z}$ is insufficiently deep or refined. Additional studies will need to be carried out. 


\section{SUMMARY OF OBSERVATIONS}

Several Reynolds-averaged Navier Stokes (RANS) turbulence models available in FLUENT [2005] have been employed to simulate staggered tube bundle flow data of Simonin and Barcouda [1986, 1988] at a Reynolds number of 18,000. The models investigated that produced converged (tolerance $<1.0$ x $10^{-6}$ ) or fairly converged results (tolerance $<1.0 \times 10^{-4}$ ) include the standard $\mathrm{k} \sim \varepsilon$ model using standard and nonequilibrium wall functions as well as an enhanced wall treatment, FLUENT [2005], the RNG and realizable $\mathrm{k} \sim \varepsilon$ models using the enhanced wall treatment, the $\mathrm{k} \sim \omega$ model using shear stress transport (SST), and the Reynolds stress model (RSM) using standard wall functions. It was found that if the default option for the RSM to use an additional equation for $\mathrm{k}$ is disabled, completely converged results are obtained. Model versions that did not produce converged results included the Spalart-Allmaras oneequation model, the standard $\mathrm{k} \sim \omega$ model and the RSM using the enhanced wall treatment. The nonequilibrium wall functions were not used after it was shown that they produced essentially the same results as the standard wall functions.

Observations that can be made from the investigation are the following:

1. The standard and realizable $\mathrm{k} \sim \varepsilon$ models using the enhanced wall treatment yield the best results for the $\mathrm{k} \sim \varepsilon$ group of models, though the results are not wholly satisfactory; the realizable model results are slightly better than for the standard model.

2. The $\mathrm{k} \sim \omega$ model using the shear stress transport feature shows generally better agreement with the data than the realizable $\mathrm{k} \sim \varepsilon$ model.

3. The Reynolds stress model using standard wall functions and no additional equation for $\mathrm{k}$ shows the best agreement overall than any of the other results shown. The RSM is the only RANS model in FLUENT that can produce anisotropic normal Reynolds stresses.

4. Overall, the v2-f model results are poorer than the realizable $\mathrm{k} \sim \varepsilon$ model and the RSM results.

5. The finer grid provided the best agreement of the three coarser girds employed, even though the coarsest grid accorded better with the FLUENT manual recommendation when using the standard wall functions. The finer grid was tuned to the recommendation in the FLUENT manual for the enhanced wall treatment.

6. Additional investigation is needed to determine if a grid can be too fine for the particular turbulence model used.

7. No model has shown to give completely satisfactory results compared to the data of Simonin and Barcouda.

8. Suitable DES calculations have not yet been produced, though preliminary results are promising.

Validation studies will continue for the other flow regimes of single and multiple jet flows into quiescent surroundings and into cross-flows using FLUENT. The turbulence models will most likely need to be compared to other data of flow in tube banks for which the confidence is higher in terms of the uncertainty. Also, it is anticipated that the more advanced method of large eddy simulation (LES) for simulating turbulence will need to be employed to compare results with RANS turbulence models. LES is currently available in FLUENT. 


\section{REFERENCES}

ASME Journal of Fluids Engineering, 144, June 1996, 427.

Benhamadouche, S. and Laurence, D., LES, coarse LES, and transient RANS comparisons on the flow across a tube bundle, International Journal of Heat and Fluid Flow, 24(4), 2003, 470-479.

ERCOFTAC-IAHR workshop, 2nd ERCOFTAC-IAHR Workshop on Refined Flow Modelling, Lisbon, Portugal, 1993.

ERCOFTAC-IAHR workshop, 3rd ERCOFTAC-IAHR Workshop on Refined Flow Modelling, UMIST (The University of Science and Technology in Manchester), Manchester, United Kingdom, 1994.

FLUENT, version 6.2.16, FLUENT Inc., 10 Cavendish Court, Centerra Resource Park, Lebanon, NH, 03766, 2005.

General Atomics, "Gas Turbine - Modular Helium Reactor (GT-MHR) Conceptual Design Description Report,” Doc. 910720, Rev. 1, July, 1996.

Hassan, Y. A., Barsamian, H. R., "Tube bundle flows with the large Eddy simulation technique in curvilinear coordinates," International Journal of Heat and Mass Transfer, 47(14-16), 2004, 30573071.

Laurence, D. personal communication, Mar. 2005.

MacDonald, P. E., J. W. Sterbentz, R. L. Sant, P. D. Bayless, R. R. Schultz, H. D. Gougar, R. L. Moore, A. M. Ougouag, and W. K. Terry, NGNP Preliminary Point Design, Results of the Initial Neutronics and Thermal-hydraulic Assessments. Tech. Report INEEL/EXT-03-00870 Rev. 1, INEEL.

Moulinec, C., Hunt, J. C. R. and Nieuwstadt, F. T. M., "Disappearing wakes and dispersion in numerically simulated flows through tube bundles," Flow, Turbulence and Combustion, 73(2), 2004, 95-116.

Rollet_Miet, P.; Laurence, D. and Ferziger, j., "LES and RANS of turbulent flow in tube bundles," International Journal of Heat and Fluid Flow, 20(3), 1999, 241-254.

Simonin, O., and Barcouda, M., "Measurements of Fully Developed Turbulent Flow across Tube Bundle," Proceedings of the Third International Symposium on Applications of Laser Anemometry to Fluid Mechanics, Lisbon, Portugal, 1986, pp. 21.5.1-21.5.5.

Simonin, O., and Barcouda, M., "Measurements and prediction of turbulent flow entering a staggered tube bundle," in: 4th International Symposium on Applications of Laser Anemometry to Fluid Mechanics, Lisbon, Portugal, paper 5.23, 1988 